\title{
RISCO E A PEQUENA PRODUÇÃO DE FUMO NO ESTADO DE ALAGOAS
}

\author{
FERNANDO JOSÉ DE LIRA
}

Orientadora: Profa. ZILDA PAES DE BARROS MATTOS

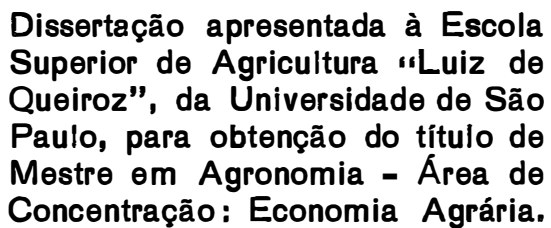

PIRA CICABA

Estado de São Paulo - Brasil

Junho - 1987 
i i.

Aos meus pais, esposa

e irmãs,

DEDICO. 
iji.

\section{AGRADECIMENTOS}

A orientação segurada Professora Zilda Paes de Barros Mattos, foi decisiva na elaboração deste trabalho. Com ela aprendi lições que muito tem auxiliado minha vida profissional. Assim, agradeço todo seu empenho e espírito de colaboração, observados nas diversas fases deste estudo.

Aos Professores do Departamento de Economia e Sociologia Rural da ESALQ/USP, as minhas considerações pelos conhecimentos que adquiri durante o curso.

Agradeço tambēm a banca Examinadora, formada pelos Professores Dr. Pedro Valentim Marques e Dr. José Dias Costa, pela leitura e sugestões feitas no trabalho. 


\section{INDICE}

Pāgina

RESUMO $\ldots \ldots \ldots \ldots \ldots \ldots \ldots \ldots \ldots \ldots \ldots \ldots \ldots \ldots \ldots \ldots \ldots \ldots$ vi

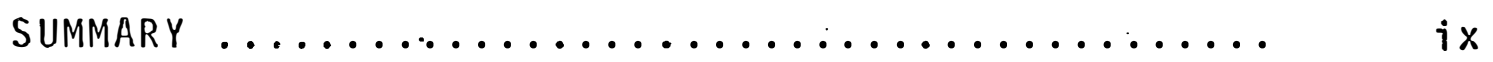

1. PROBLEMA E OBJETIVOS ............................ 01

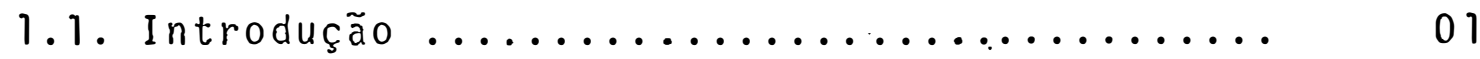

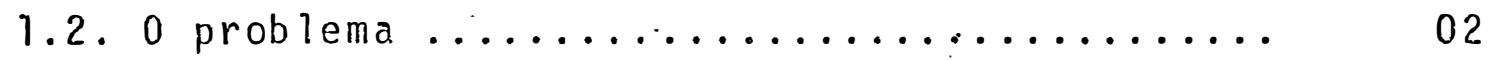

1.3. Objetivos ...................... 04

2. REVISAO DE LITERATURA 06

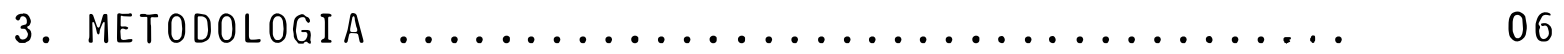

3.1. Pressuposições básicas do modelo .........

3.2. Vantagens do modelo ................ 14

4. REGIAO DE ESTUdO E A AMOSTRA ................ 17

4.1. Características gerais da região .......... 17

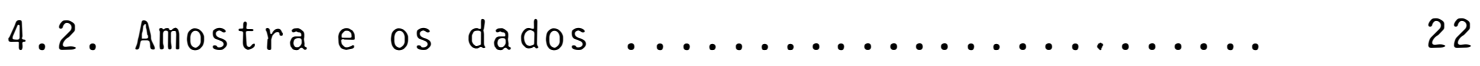

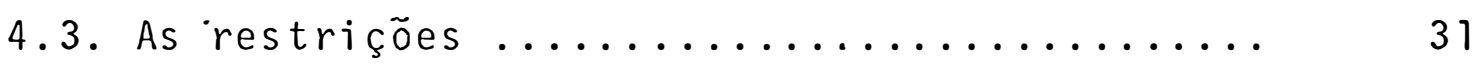

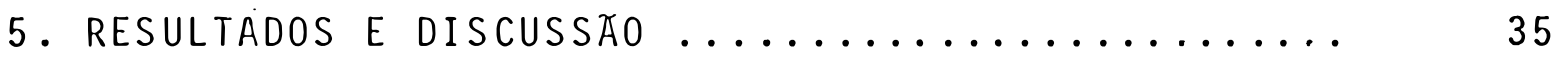

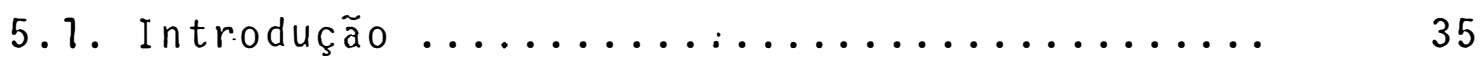

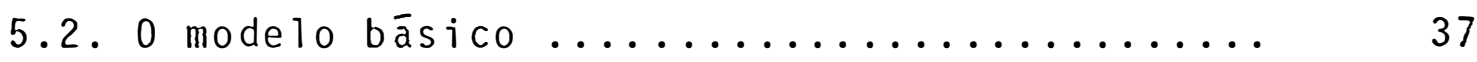

5.3. 0 modelo com restrição de consumo modificada 44

6. CONCLUSOES E RECOMENDAÇOES ................. 51

LITERATURA CITADA .................. 55

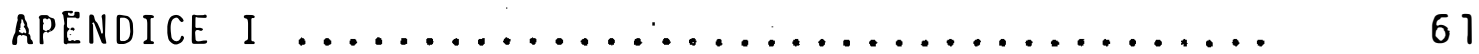

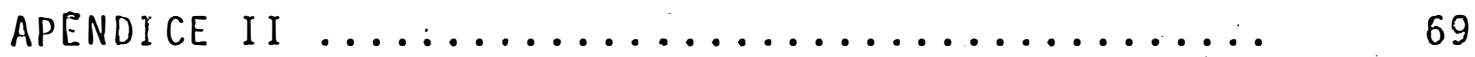

APENDICE III $\ldots \ldots \ldots \ldots \ldots \ldots \ldots \ldots \ldots \ldots \ldots \ldots \ldots \ldots \ldots \ldots \ldots \ldots \ldots$ 


\section{LISTA DE TABELAS}

TABELA NO

pāgina

01 Nūmero, ārea média, participação percentual na quantidade total pro zida de fumo, na ārea plantada e no valor da produção, dos es tabelecimentos agropecuārios da região de Arapiraca segundo extrato de ārea, Estado de Alagoas, $1980 \ldots \ldots \ldots \ldots \ldots \ldots \ldots \ldots \ldots \ldots \ldots \ldots$

02 Desvio absoluto médio, coeficiente de variação e margem bruta esperada de consōrcios selecionados, pequenos fumicultores. Arapirava, Alagoas, ano agrícola $1983 \ldots .$.

03 Combinações das atividades eficientes referentes a nove pianos de fronteira eficiente, pequena produção de fumo. Arapiraca, Es tado de Alagoas, ano agrícola 1983 .......

04 Quantidade utilizada e disponivel de recur sos nos planos ótimos da fronteira eficiente, pequena produção de fumo. Arapiraca, Es tado de Alagoas, ano agrícola $1983 \ldots . . \ldots 42$

05 Combinação das atividades referentes a nove planos de fronteira eficiente (com opção de compra de alimentos), pequena produção de fumo. Arapiraca, Estado de Alagoas, ano

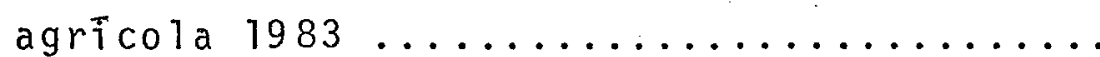

06 Quantidade utilizada e disponivel de recursos nos planos ótimos da fronteira eficiente, pequena produçäo de fumo. Arapiraca, Es tado de Alagoas, ano agrĩcola $1983 \ldots . . .$. 


\section{LISTA DE FIGURAS}

FIGURA NQ

Pāgina

01 Municîpios que compõem a região fumageira de Arapiraca, Alagoas $\ldots \ldots \ldots \ldots \ldots \ldots \ldots \ldots$

02 Fronteira eficiente, pequenos produtores de fumo, Arapiraca, Alagoas, ano agrícola 1983.

- 03 Fronteiras eficientes dos modelos bäsico e com opção de compra de alimentos, pequenos produtores de fumo. Arapiraca, Alagoas, ano

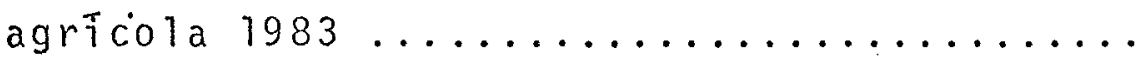


vi i .

\section{RISCO E PEQUENA PRODUÇAO DE FUMO NO ESTADO DE ALAgOAS}

Autor: FERNANDO JOSE DE LIRA

Orientadora: Profạ Drạ Zjłda Paes de Barros Mattos

\section{RESUMO}

Este estudo teve como objetivo principal estudar o efeito da diversificação da produção na renda e variabilidade da renda. Mais especificamente, os objetivos foram:

a) tentar reproduzir o processo de tomada de decisão de, um grupo de pequenos produtores através do uso de um modelo de programação linear, incorporando risco; b) identificar, com base nos resultados obtidos em a- os recursos mais limitantes do modelo; e c) investigar o efeito de uma maior disponibilidade de tais recursos sobre a renda e variabilidade da renda.

A ārea escolhida para estudo foi a região fuma geira de Arapiraca, no Estado. de Alagoas. Os dados foram coletados através de entrevistas com pequenos produtores de até 10 hectares, realizadas em três épocas distintas dos ciclos produtivos das culturas, no ano agrícola de 1983.

os resultados da pesquisa mostraram que os agri cultores, na sua quase totalidade, adotam sistemas consorcia dos de culturas, incluindo nesses consōrcios, culturas de sub sistência.

os planos contidos na fronteira eficiente gerada pelo modelo foram bastante semelhantes aos planos encontrados na anlostra. 
os recursos terra, mão-de-obra e capital não foram limitantes no modelo. Os resultados mostraram que as restrições de consumo mīnimo proveniente da prōpria produção. foram as mais limitantes na geração da fronteira eficiente.

Décidiu-se, assim, estudar o efeito que um "rẹ laxamento" daquelas restrições teria sobre os níveis de lucro esperado e riscos das combinações de consōrcios, introduzindo -se no modelo opções de compra daqueles alimentos.

os resultados mostraram que a compra de parte do consumo de feijão e de batata permitiu que, aos mesmos niveis de lucro esperado, planos mais eficientes fossem obtidos, contrariando a hipótese de que o plantio de alimentos para au toconsumo contribui para diminuir o risco da pequena produção. 


\section{RISK AND THE SMALL TOBACCO PRODUCTION IN THE STATE} OF ALAGOAS, BRAZIL

Author: FERNANDO JOSE DE LIRA

Adviser: Profa Drạ Zilda Paes de Barros Mattos

\section{SUMMARY}

The main objective. of this study was to investigate the effect of farm diversification on income and income variability. More specifically, the objectives were: a) to use a linear programming model, incorporating rjsk, in an attempt to reproduce farmers decision making. process; b) based on the results of $\underline{a}$, to identify the most limiting resources in the model; and c) to investigate the effect of a greater availability of those resources on income anu income variability.

The study area was the tobacco production area of Arapiraca, State of Alagoas. The data used in the study were collected through personal interviews with farmers (owning up to 10 hectares of lard), in three different production cycle points, during the 1983 agricultural year.

The results of the study showed that almost all farmers cultivate crop "consorcium", including subsistence crops.

The production plan on the efficient frontier generated by the model were very similar to. the ones selected by farmers. 
The productive resources land," labor, and capital were not limiting in the model. The results showed that restrictions on consumption coming from farm production were the most limiting in the generation of the efficient frontier.

Thus, a modification on the consumption restrictions was introduced by allowing food to be bought (besides coming from production), in order to investigate its effect upon income and income variability.

The results showed that buying part of edible beans and potatioes consumed, more efficient plans were obtained at the same prior income levels, which contradicts the belief that the practice of cultivating subsistence crops contributes to reduce risk of small production. 


\section{CAPITULO 1 \\ O PROBLEMA E OBJETIVOS}

\section{I. INTRODUGÃO}

Nos $\bar{u} l$ timos anos, o Nordeste atingiu um crescimento bastante razoāvel, com seu produto interno bruto crescendo a uma taxa de $6,9 \%$ ao ano. Embora crescendo mais 1enta mente que outros setores, a agricultura também apresentou crescimento considerável, à uma taxa média de $4,4 \%$ ao ano (SUDE$\cdot N E, 1983)$.

A nivel nacional, a agricultura regional gera mais de $20 \%$ da renda agrícola do Brâsil, enquanto que sua produção industrial não chega a atingir $7 \%$ do total nacional (SUDENE, 1983). Essa posição de destaque reservada à agricultura tem característizado a Região Nordestina como uma região essencialmente agrícola.

Mesmo com essa importāncia, a agricultura nordestina mantēm baixos níveis de produção e produtividade, além de estar sujeita a grandes variações de clima que afetam sobremaneira a produção e renda do setor rural. Muito embora represente um quinto da produção agrícola do país, a agricul- 
tura nordestina não chega a suprir as necessidades bāsicas de alimentos da região e, em anos recentes, tem também apresentá do uma perda de importância no conjunto das exportações bras leiras (SUDENE, 1983).

A pequena propriedade tem assumido importante papel como produtora de alimentos e matéria prima na agricultura nordestina. Dados da Fundação Instituto Brasileiro de Geo grafia e Estatística (FIBGE, 1980) mostram que os imōveis com menos de 10 ha reservam $65,8 \%$ de sua área para produzir alimentos, enquanto que nos de 500 a 1.000 ha, esse percentual é de apenas $8,4 \%$. Em relação aos produtos de transformação jandustrial, o percetual $\bar{e}$ de $16,7 \%$ para os imóveis de menos de 10 ha, contra $8,3 \%$ para os de 500 a 1.000 ha.

os anos de seca e de preços baixos prejudicam a produção agrícola como um todo, mas é essencialmente a pro- dução de subsistência, fonte básica da renda real do produtor, a mais severamente atingida. Este fato se reveste da maior importáncia quando se considera a pequena propriedade no Nordeste, a qual assume papel preponderante na agricultura da região, não somente como fornecedora de alimentos e matéria prima, mas tambēm como fonte de ocupação da força de trabalho (SUDENE, 1983).

\subsection{Problema}

A variabilidade da renda decorrente das condições climáticas, biolögicas e oscilações dos preços dos produ 
tos e insumos agrícolas, presente em todas as atividades agri colas de produção, ē frequentemente denominada risco. Sua pre sença impõe restrições à organização. Este fato se reveste. de maior importāncia quando se considera a pequena propriedade do Nordeste, a qual assume papel preponderante na agricultura da região, não somente como fornecedora de alimento e mä téria-prima, mas também como fonte de ocupação da força de trabalho.

Arapiraca, microregião localizada no agreste de Alagoas, é conhecida tradicionalmente como produtora de fu mo em folha e corda, tendo nessa exploração o produto agríicola de maior importância económica e social.

Conforme dados da FIBGE (1980), o fumo da microregião de Arapiraca participa com mais de $80 \%$ do valor bru to da produção, em todos os estratos de ārea, representando $95 \%$ do fumo produzido em Alagoas e $35 \%$ em relação ao Nordeste. E esta uma atividá de agrícola praticada em sua maioria por pequenos produtores. Nos perîodos de prolongamento da estiagem e nos anos em que o: fumo apresenta cotação de preços baixos, os agricultores passam por sērias dificuldades, o que se reflete em toda a região na forma de desemprego e, portanto, em baixo nivel de renda das demais atividades agrícolas e da atividade comercial.

Apesar da importāncia da pequena propriedade que cultiva fumo no Estado, assim como da gravidade dos efeitos das se cas que assolam a região, pouco se conhece a respeoto do processo decisório dos agricultores frente a tais adversidades. Sabe-se, por exemplo, que alguns agricultores, na tentativa 
de reduzir o risco da produção de fumo, têm procurado introdu zir em suas propriedades, o cultivo de outros produtos como algodão, feijão, milho e mandioca. Entretanto, não existem estudos que tenham tentado medir o efeito de tai diversifica ção sobre o grau de risco das combinações de atividades.

Na verdade, hà uma grande. lacuna na literatura com respeito a estudos que tratam dos problemas dos pequenos produtores de fumo, em Alagoas.

Assim, espera-se que um maior conhecimento do processo de decisão desses agricultores, assim como das limitações de recursios a que estão sujeitos, possam servir de sub sídio para futuras políticas para a regĩo.

\subsection{OBJETIVOS}

o objetivo geral a que se propõe este trabalho é estudar os efeitos da diversificação de culturas na renda e risco de uma amostra de pequenos fumicultores da microregião de Arapiraca, Estado de Alagoas. Os objetivos específícos são:

1. Estimar a renda bruta esperada e a variabiTidade da renda (como medida de risco) para cada atividade de produção da amostra.

2. Tentar reproduzir o processo de tomada de 
decisão do agricultor, usando um modelo de programação matemática, com risco.

3. Identificar os recursos mais limitantes para os pequenos fumicultores e estudar o efeito de uma maior disponibilidade dos mesmos sobre a renda e risco das combinações de atividades encontradas em 2 . 


\section{CAPITULO 2}

\section{REVISÃO DE LITERATURA}

Vārios trabalhos na ārea de economia da produção foram baseados em estimativas de função de produção, estị mando o valor do produto marginal dos fatores a partir de dados extraidos de cortes transversais no tempo. Quase que na sua totalidade, esses trabalhos usam como modelo a função de - produção Cobb-Douglas. Visam analisar a eficiência económica da alocação de recursos, sob o pressuposto de que os agricultores agem no sentido de maximizar lucro.

Como afirma DILLON \& ANDERSON (1977), a teoria neoclássica da decisão, não levando em conta o risco das atividades agrícolas, não permite uma anālise real do comporta mento económico de agricultores de paises em desenvolvimento.

Esses estudos, apesar da contribuição que ofereceram à anālise econômica de problemas específicos da agricultura, não consideraram o risco como variável importante no processo de tomada de decisão do agricultor.

os preços e produtividade utilizadas nesses 
estudos eram dados "ex-post" e indicavam, quase sempre, ineficiência no uso de recursos. Vārios estudos foram feitos nes sa linha no Brasil (JUNQUEIRA, 1961; TEIXEIRA FILHO, 1962; T음 LINI, 1962; VEIGA, 1965; ENGLER, 1968).

Existe também uma literatura abundante e um nū mero significativo de trabalhos que se baseiam na pressuposição da maximização de renda, empregando programação linear. Dentre estes trabalhos incluem-se.os estudos de ENGLER (1971), BARB OSA (1972) e NEVES (1972).

0 modelo convencional de maximização de renda que utiliza a programação linear, por ignorar o fator risco, pode levar a um plano de atividade considerado inaceitável pe 10 agricultor. A não consideração do fator risco, além de possibilitar uma maior variação na renda do produtor, pode resultar em muito mais especicialização do que ocorre na -prātica.

LIPTON (1968) argumenta que muitos agricultores, especialmente pequenos produtores, preferem atividades de menor risco, mesmo que menos lucrativas. Para esses produtores, a preocupação quando da tomada de decisão não se resume, como quer a teoria neoclássica tradicional, em apenas obter um maior nível de renda, mas sobretudo em evitar grandes variacooses no nivel de renda das atividades escolhidas.

Na mesma linha de raciocínio adotada por Lipton, PASTORE (1975) coloca que são muitos os agricultores que renunciam a alternativas de produção que thes prometem maiores niveis de renda, principalmente porque, em possuindo alto risco, podem comprometer sua sobrevivência. 
Outros estudos sobre tomada de decisão têm mos trado que produtores podem não visar apenas a maximizacão da renda por estarem as mesmas associadas a elevados graus de ris CO (DILLON \& ANDERSON, 1971).

Mesmo com as 1 imitações que apresentam como mo delo auxiliar à tomada de decisão, a técnica da anālise marginal constitui um capituro importante no estudo da economia da produçao, na medida em que fornece elementos à aprendizagem e dominio de outras técnicas mais sofisticadas. A inclusão, por exemplo, de fatores meteorológicos em estudos econométricos ē hoje tida como necessāria, pois ao fator clima estā associada parte significativa da variação dos retornos das culturas nos diversos anos agrícolas.

Com essa nova visão, värios estudos foram feitos empregando añ̄ise de regressão, que define uma função de produção utilizando variāveis mais representativas das con dições locais. Entre outros, temos trabalhos realizados por PASCALI \& MOTA (1966); DUARTE (1975) e FONSECA (1976).

Em tempos mais recentes, entretanto, atenção tem sido dedicada à incorporação do elemento risco em modelos de programą̧ão linear. Nesse sentido, vários estudos foram realizados sendo que merecem particular destaque HAZEL (1971); HEYER (1972); LOW (1974); WIENS (1974); HAZEL \& SCANDIZZO (1974); SANDERS \& HOLANDA (1975); e KUTELLER \& SANDIZZO (1976).

Esses estudos, apesar de estarem começando a ser adequadamente considerado em trabalhos e planos relacio- 
nados com a agricultura brasileira, têm mostrado que é muito mais realista estudar o processo de tomada de decisão quando se parte da premissa de que os agricultores, ao decidirem por uma determinada atividade agrícola, levam em cónsideração os aspectos de risco associados a.cada retorno.

Portanto, do ponto de vista da realidade a que estão submetidos os agricultores, não se pode deixar de levar em conta os fatores responsāveis pela incerteza dos resultados económicos, isto é, as flutuações de preços e as variações nas quantidades produzidas, que resultam em oscilações na renda bruta por hectare.

HOMEM DE MELLO \& CANTON (1980), estudando o risco na agricultura brasileira, concluiram que, para as culturas arroz, algodão, feijão e milho, o risco devido às condiçöes climáticas adversas é mais elevado no Nordeste, do que - em relaçãó à região Sul do país. Concluíram ainda que essa situação arriscada cria, para os produtores, uma série de dificuldades em termos de nivel de renda e de seu crescimento.

Apesar da agricultura nordestina estar submeti da a condições de instabilidade ćlimática e econōmica, poucos trabalhos tēm sido feitos nessa área. Na sua quase totalidade, os trabalhos nessa linha de pesquisa, no Brasil, têm sido realizados na região Sul, Sudeste e Centro Sul, mesmo porque as instituições de maior relevāncia em pesquisas cientificas do país estão localizadas nessas regiões.

Entretanto, poucas regiões no Brasil apre sentam condições de meio ambiente tão desfavoráveis à agricul- 
tura como o Nordeste. De acordo com a colocação de DILLON \& MESQUITA (1976), as populações rurais do Nordeste sofrem seve ras pressões de natureza climätica, a ponto de gerar nessas populações, um modo, de vida onde o risco desempenha papel de alta relevāncia éconōmica e soçial, constituindo-se num fator básico de decisões e de comportamento. Segundo HOMEM DE MELLO \& CAN TON (1980) muitas evidēncias tēm mostrado que os pequenos produtores, principalmente no Nordeste, possuem maior grau de aversão ao risco que os grandes produtores.

Para alguns agricultores que possuem, além da atividade agrícola, outros maios de subsistência, a aversão ao risco se dá em menor grau, o que talvez explique o fato de alguns fumicultores que não possuem outros meios de subsis tência além da atividade agrícola, diversificarem bastante sua produção, enquanto que outros mantém em suas propriedades prä ticamente uma ūnica exploração. Nesse sentido, DILLON \& SCAî DIZZO (1976) estudando o comportamento de pequenos produtores no Nordeste, concluem que parece haver uma diferença qualitativa entre casos de subsistência assegurada e da subsistencia não assegurada. Segundo esses autores, nenhum agricultor demonstrou ter preferência por risco quando sua subsistência es tava comprometida, enquanto um número expressivo de produtores, parece estar desejoso de tomar risco quando possuem subsistência assegurada.

Os pequenos produtores da região objeto deste estudo, quando não usam a cultura do fumo como única explora ção, têm adotado um nūmero grande de explorações, que 
geralmente incluem fumo, feijão, batata doce, algodão e mandioca.

A esse respeito PIRES \& PERES (1981) menciona que um nümero grande de explorações, como medida de estabilização de renda, pode impedir os agricultores de utilizarem as vantagens decorrentes de uma diversificação em menor grau. Is so porque a necessidade do uso de fatores escassos em diversas culturas pode levar o agricultor a usā-los em quantidades menores que a requerida por aquelas culturas de produtivi dade mais alta.

HOPKINS (1952) diz que a diversificação reşul-. tante de um bom plano de rotação de culturas durante. o ano agrícola pode reduzir as perdas devidas às más condições de tempo e a preços desfavoräveis.

No presente trabalho, propõe-se dar alguma con - tribuição para uma compreensão melhor do comportamento dos pequenos produtores de fumo da região de Arapiraca, Estado de Alagoas. Pretende-se, assim, estudar o efeito da diversifica ção de culturas no nível e variabilidade da renda. 


\section{CAPITULO 3}

\section{METODOLOGIA}

0 que se propõe neste estudo, é analisar os efeitos da diversificação de culturas na renda e variabilidadade da renda de pequenos produtores fumicultores. Para alcançar tal objetivo, serā utilizada a metodologia da programação linear, desenvolvida por HAZELL (1971), onde risco 'é uma variāvel importante de decisão.

$$
0 \text { modelo escolhido para este estudo leva em }
$$

consideração a chamada anālise de atividades. Consiste basicamente na determinação da fronteira eficiente que indica as diversas combinações de atividades, seus retornos e respecti vos graus de risco. A medida de risco nesse modelo é dada pelo desvio absoluto ém relação à média (HAZZEL, 1971).

3.1. Pressuposigoes basicas do modelo

Para SOARES \& MEYER (1979), o critério da pro- 
gramação linear com risco, leva em conta basicamente as seguintes pressuposições:

1. 0 administrador da propriedade agrícolá, no momento da tomada de decisão, considera o resultado de qualquer atividade produtiva em termos de probabilidade significando que o retorno da atividade considerada segue uma distribuição de probabilidade;

2. Quando da avaliação de diversas combinações aiternativas de atividades produtivas, o ad ministrador decide entre os diferentes $p_{i}$ anos de atividades, considerando apenas o va lor esperado e a variancia associada ao retorno;

3. O modelo tambēm pressupõe que os agricultores são aversos ao risco, significando dizer que niveis crescentes de renda esperada são necessārios para compensar niveis mais elevados de risco;

4. Retornos esperados mais altos são preferíveis aos retornos esperados mais baixos;

5. A um dado nivel de retorno esperado, uma menor variāncia é preferível a uma variància maior;

6. Há uma taxa marginal de substituição decres cente entre renda esperada e sua variàn cia. 


\subsection{VANTAgENS DO MODELO}

1. A não consideração do fatos risco em modelos convencionais de maximização de renda pode resultar em maior especialização do que, na verdade, ocorre na prática, bem como pode conduzir a uma maior variação na renda da propriedade;

2. A programaçã் linear convencional, como modelo maximizador da renda que ignora o fator risco, pode levar a um plano ötimo "de atividades, considerado não realista pelo agricultor;

3. Os modelos estocásticos de programaçăo mate mática, ao procurarem aumentar a renda ao mesmo tempo em que tenta diminuir suas variações, permite uma melhor alocação de recursos e combinação de atividades na propriedade.

Para PIRES \& PERES (1981), o modelo apresenta as seguintes limitações:

1. O modelo utilizado só leva em conta o risco associado aos retornos, não considerando o risco associado aos preços dos insumos;

2. Na determinação da fronteira eficiente, par - te-se de um pressuposto bäsico, de que o 
agricultor é averso ao risco, ou seja, não se utilizam informações sobre o grau de aver são ao risco dos agricultores;

3. Parte também do pressuposto de que as probabilidades de ocorréncia de eventos maio res que a média são iguais às ocorrências de eventos menores que a mēdia, não sendo considerado o aspecto assimétrico da distri buição.

o modelo proposto por HAZELL (1971) pode ser representado por:

$$
\operatorname{minimizar} \frac{|z|}{2}=\sum_{v=1}^{m} q_{v}
$$

sujeito a:

$$
\begin{aligned}
& \sum_{j=1}^{n} x_{j} Q_{v j}+q_{v} \geq 0 \\
& \sum_{j=1}^{n} a_{j} x_{j}=r \\
& \underset{j=1}{n} a_{i j} x_{j} \leq b_{i}(i=1, \ldots, t) \\
& x_{j} \geq 0, \quad q_{v} \geq 0
\end{aligned}
$$

No presente trabalho, será utilizado o modelo proposto por HAZELL (1971), onde:

$Z$ = soma dos desvios absolutos com relação às médias das receitas brutas das atividades de produção, em cruzeiros de 1983 
16.

$q_{v}=$ variāvel auxiliar que mede a soma dos valores absolutos dos desvios negativos, no ano $v$;

$x_{j}=$ nīvel da j-ēsima atividade;

$Q_{v j}=$ desvio em relação à receita mêdia dos cinco anos (1978 a 1982) da atividade j no ano $v$; ou seja,

$$
Q_{v j}=\left(R_{v j}-\bar{R}_{j}\right)(v=1, \ldots, m ; j=1, \ldots, n)
$$

onde:

$R_{v j}=$ receita-bruta por hectare da atividade $k$, no ano $v$;

$\bar{R}_{j}$ = receita mēdia esperada da atividade $j$;

$r$ = receita líquida da propriedade (valor parametrizado);

$a_{i j}=$ quantidade de insumo necessāria para produzir uma unidade da atividade $j$;

$b_{i}=$ nĩvel da i-ésima restrição;

$a_{j}=$ contribuição da atividade $j$ para a composição da receita esperada da empresa.

Para cada nîvel da receita liqquisa esperada $(r)$, é selecionada uma combinação de atividades que possui o menor desvio absoluto. o lugar geométrico dos pontos assim gerados, recebe o nome de fronteira eficiente. 


\section{CAPÍTULO 4}

\section{A REGIÃO DE ESTUDO E A AMOSTRA}

\subsection{Caracteristicas gerais da regiño}

Situada na Zona do Agreste do Estado de Alagoas, a região fumageira ocupa uma extensão de $1.905 \mathrm{~km}^{2}$ cons tituída dos municípios de Arapiraca, Coite do Nöia, Feira Gran de, Girau do Ponciano, Lagoa da Canoa, Limoeiro de Anadia e Taquerana, mostrados na Figura 1. O municipio mais distante da capital do Estado, Maceiō, é Girau do Ponciano (166 km), e o. mais próximo Taquarana da qual dista $118 \mathrm{~km}$. Esta região foi escolhida para estudo, não sō porque é a mais importante em produção de fumo do Estado, mas sobretudo em virtude da ren da advinda da cultura do fumo sofrer fortes oscilações decorrentes das variações nos preços pagos ao produtor e das adver sidades do clima.

Segundo a classificação climática de Guassen, que se baseia no rítmo das temperaturas e das precipitaçöes durante o ano, utilizando-se de mëdias mensais e consideran- 
18.

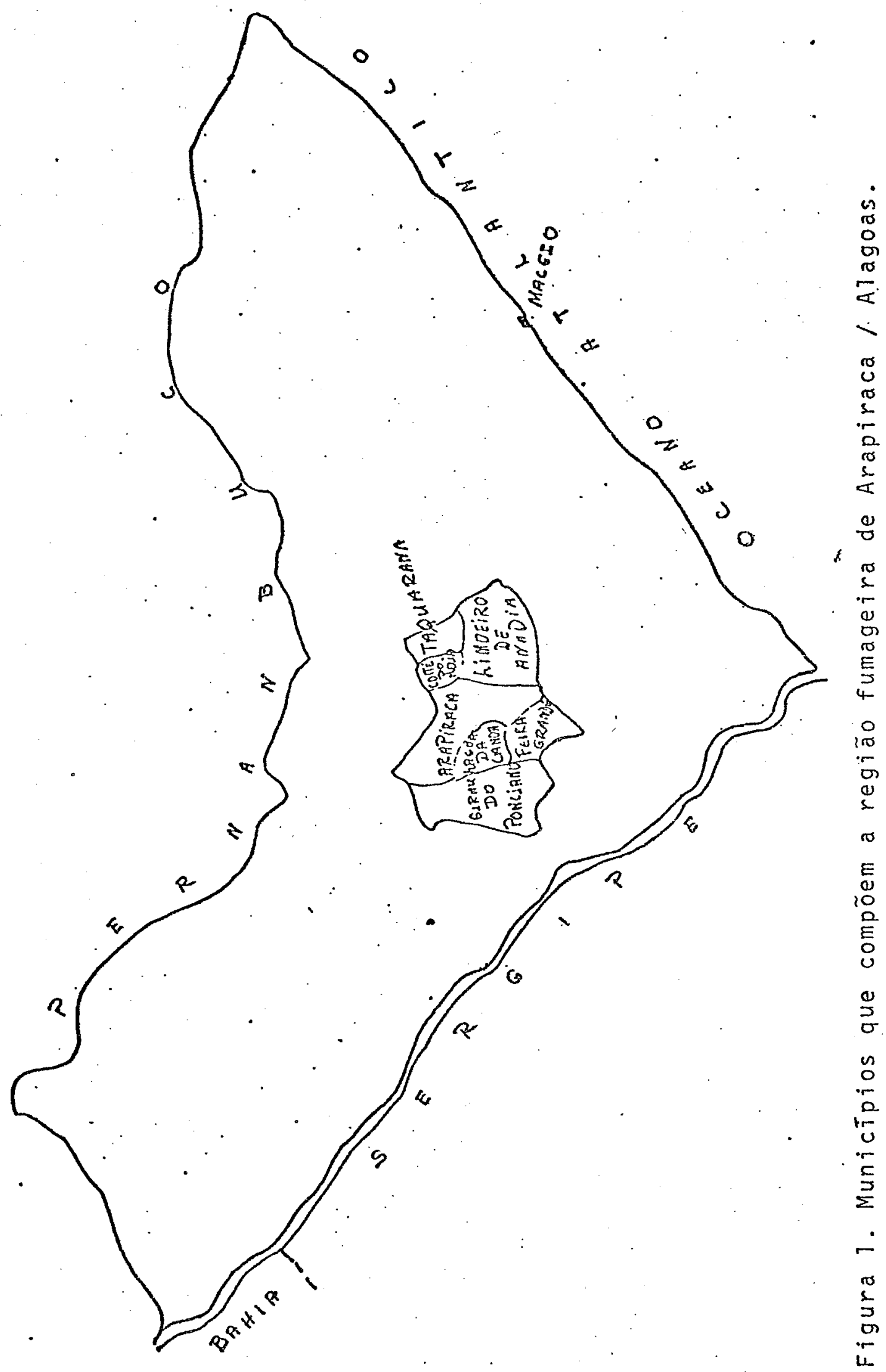


do os estados favorāveis e desfavorāveis à vegetação, a região em estudo apresenta clima mediterrāneo, quente ou nordestino de seca alternada de verão. o nūmero de meses secos varia de três a cinco. A precipitaçăo pluviomētrica é relativamente homogênea, serido sua. máxima em. torno de $1.100 \mathrm{~mm}$ anuais e minima de $700 \mathrm{~mm}$ anuais. Nos anos regulares de chuvas, mais de $80 \%$ das precipitações ocorrem no período : entre março e setembro. A partir deste mês sucedem-se os meses secos e de temperaturas elevadas. A temperatura média anual das māximas é de 330 C, e a média anual das minimas fica em torno de 200C. A temperatura média mais baixa ocorre em juTho, ficando em torno de $170 \mathrm{C}$. A umidade relativa do ar apré senta indices baixos, variando entre 76 e $80 \%$.

A utilização das terras da ārea em estudo compreende lavouras, com $63,9 \%$, pastagens plantadas, $16,2 \%$ pas- tagem natural e semicultura, $3,4 \%$. Esses dados, fornecidos pela Comissão Estadual do Planejamento Agrícola (CEPA, 1980), mostram que a ārea é bastante propícia ao uso agrícola.

Dadas as condições de precipitação, as culturas de ciclo longo ou aquelas plantadas quase no final do período chuvoso, como ocorre frequentemente com o fumo, quando não são irrigadas, podem ser afetadas pelos meses secos, salvo o algodão arbōreo e palma forrageira, que são culturas adaptadas às condições do meio ambiente da região.

A região é de transição entre a zona da Mata e a zona sertaneja. Por esta razão, o solo predominante na área é o latossol vermelho amarelo distrófico. Sua vegetação é for 
mada de florestas e caatingas. As florestas são compostas de subparenifólia, subcaducifólia e caducifólia, enquanto a caatinga é representada pela hipoxerófilia.

0 çenso demogrāfico de 1980 mostra que, possuindo uma ārea de $1.905 \mathrm{~km}^{2}$, a população da região fumage ra é de 229.561 habitantes. A ocupação.dessa ārea pela população apresenta características e tendências deperidentes da utilização da terra. Em todos os municĩpios, com exceção de Arapiraca, a população é predominantemente rural. Há uma gran de concentração populacional em torno do municĩpio de Arapira ca, polo de difusão, convergência e distribuição do fumo. Ne $\underline{s}$ te municipio hä um comërcio vigoroso, existência de diversas fābricas de manufatura, serratherias, usinas de beneficiamento de arroz, algodão e indūstria de transformação do fumo.

No setor de comunicação, a região está relativamente bem servida, principalmente com relação aos serviços prestados pela Telecomunicações do Alagoas S/A (TELASA), Empresa Brasileira de Correios e Telégrafos (EBCT), que cobrem toda a área, permitindo ligação com os principais centros urbanos do Estado. A região possui ainda duas emissoras de rádio, além de 3 (três) canais de televisão provenientes da Ca pital do Estado e de Aracajū, no Estado de Sergipe. .

Todos os municipios estão ligados à Capital e à cidade de Arapiraca por rodovias asfaltadas, de vital importáncia no escoamento da produção pelo sistema rodoviário, cujos meios mais comuns são caminhões, camionetas, jeeps, etc., 
fazendo o transporte de produtos e pessoas, principalmente en tre os municípios da região.

A região é relativamente bem servida de entides financeiras. Em Arapiraca, centro polarizado da região, encontram-se agências do Banco. do Brasil, do Banco do Nordeste, Banco do Estado de Alagoas, a Tém de um razoāvel número de agências bancárias da rede privada, todas elas com lintia de crēdito para agropecuāria. Além dessa concentração na sede do municipio de Arapiraca, existem postos de serviços do Banco do Brasil em todos os demais municípios da ārea em estudo. Os serviços de assisténcia técnica são executa dos, na região, pela Empresa de Assistência Técnica e Extensão Rural de Alagoas (EMATER), que atualmente mantém escritō rios em todos os municípios.

Convém ainda mencionar que a região escolhida é uma ārea bastante dinâmica na comercialização de insumos agropecuários e implementos agrícolas de firmas particulares.

A economia agrícola da região fumageira fundamenta-se principalmente na produção da lavoura. Dados de 1980, da CEPA, mostrạ que. o fumio é considerado o suporte eco nômico da região, apresentando a mais expressiva participação (em torno de 60\%) na formação do Valor Bruto da Produção (VBP) de lavouras.

A cultura da mandioca acha-se disseminada praticamente em quase toda a região fumageira, ocupando o segundo lugar em importância econômića, com uma participação aproximada de $16 \%$ no VBP das lavouras. 
o algodão herbāceo, cultivado geralmente em consōrcio com o fumo, tem uma ārea de cultivo se expandindo nos $\bar{u}$ timos anos, apresentando-se como o terceiro. produto mais importante, com uma participação de cerca de $10 \%$ na formação do VBP da lavoura da regiãa.

o feijão, mitho e batata doce, constituem produtos de sustentação das populações rurais e urbanas. Estes produtos, juntos, participam com cerca de $7 \%$ no VBP das lavouras.

Vale mencionar as culturas de abacaxi e inhame como atividades agrícolas ainda incipientes em termos, de ārea cultivada, podendo-se mesmo afirmar que encontram-se em fase de introdução.

A bovinocultura de corte e leite como ativida des econômicas, são praticamente inexistentes nas pequenas unidades de produção, surgindo naquelas de maior tamanho como atividades secundārias e complementares da renda dos agricultores.

0 fumo é produzido com uma tecnologia semelhan te para todos os pequenos produtiores que, em sua maioria, ut lizam o consōrcio com o feijão ou algodão herbáceo. A produção destina-se, em sua maior parte, ao mercado interno e externo de fumo em folha, completada pelo fumo em corda para o consumo interno.

4.2. Amostra e os Dados

Neste estudo foi utilizada uma amostra compos- 
ta de 50 propriedades agrícolas, onde todos os agricultores consultados são produtores de fumo assistidos pela Empresa de Assistência Ténica e Extensão Rural (EMATER).

0 estudo refere-se a agricultores produtores de fumo, proprietārios, com menos de 10 hectares de ārea pos suída, por representarem a maioria dos produtores de fumo da região. Como mostra a Tabela 1 , os produtores incluídos nesse extrato de ärea representam mais de $87 \%$ de todos os produtores de fumo.

Detendo uma ārea de $26,22 \%$ da ārea total da re gião, estes produtores dedicam $53,09 \%$ de sua área à prodyção de fumo, chegando a contribuir com $55,44 \%$ do total da quanti-. dade produzida, o que representa aproximadamente $54 \%$ do valor total da produção. Por sua vez, os produtores com mais de 10 hectares, que representam $73,38 \%$ da ārea total da região, de- dicam aproximadamente 46,91\% dessa ārea à produção de fumo, participando com apenas $44,56 \%$ do total da quantidade produzida de fumo.

Da observação direta da Tabela 1 , depreende-se que os pequenos produtores da amostra deste estudo têm uma participação relativa no cultivo e produção de fumo, bastante significativa.

0 universo pesquisado constou desses produtores, em sete municípios que compõem a região fumageira. os agricultores foram selecionados ao acaso, através de uma lista de nomes fornecida pela EMATER-AL. 


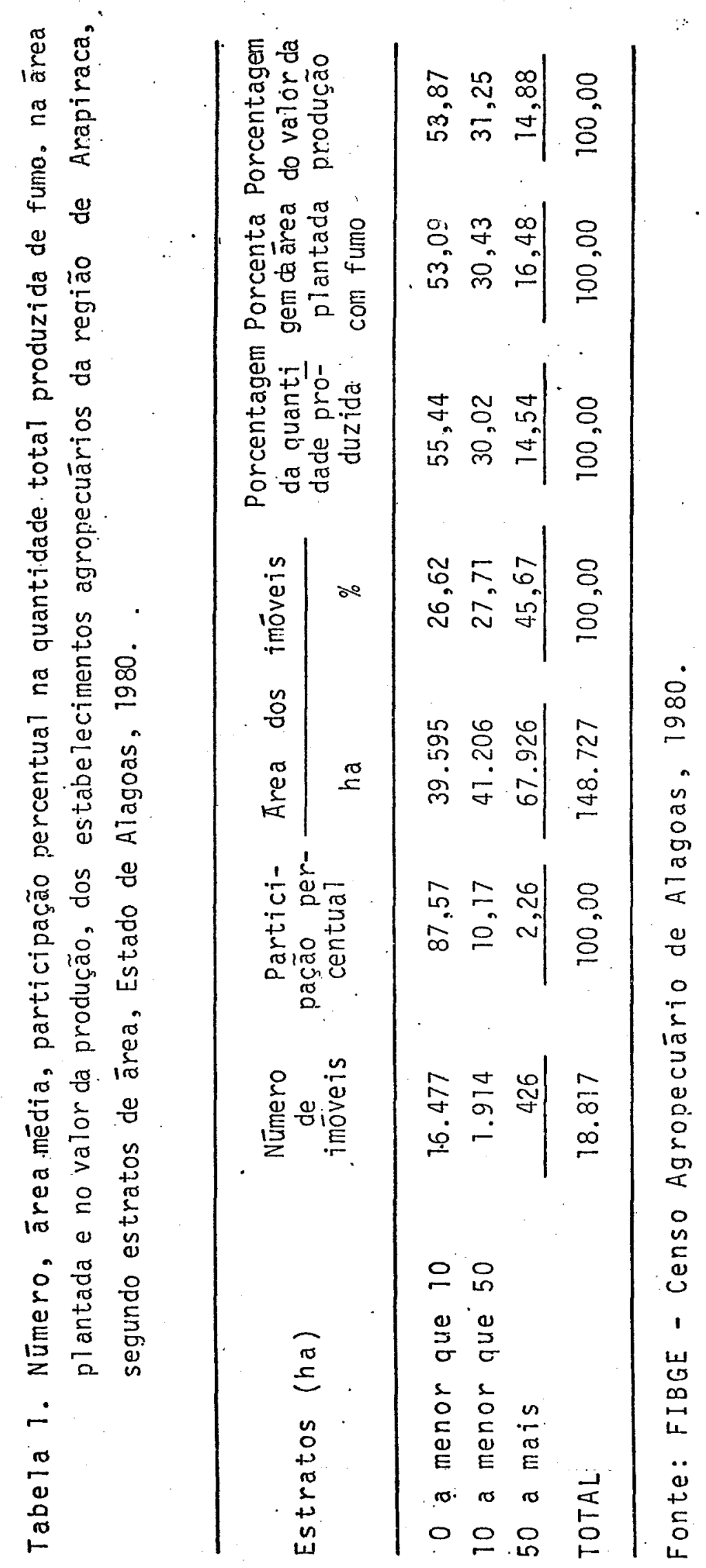


Os dados empregados foram coletados através de dois tipos de questionários complementares, sendo realizadas en trevistas com os mesmos agricultores, em épocas diferentes do ano agrícola.

0 primeiro questionärio, aplicado em jultio de 1983, constou de uma amostra de 60 produtores. A segunda entrevista, realizada em janeiro de 1984, atingiu apenas 50 dos agricultores entrevistados anteriormente porque 10 agriculto res haviam vendido suas propriedades, em face da grande seca que atingia toda a região.

o levantamento traz informações sobré os diversos estágios do ciclo produtivo. Na primeira coleta, extrai-se informações sobre preparo do solo, sementeira e plan tio das cuituras praticadas pelos fumicultores. 0 . segundo questionário forneceu dados sobre tratos culturais, colheita e comerciálização.

Levando-se em consideração as disponibidadades de recursos, diferenças nas exigēncias e remuneração da mãode-obra, ēpoca de semeadura do fumo, preparo do solo, plantio, tratos culturais e cọtheita das culturas estudadas, o ano agri cola foi dividido em quatro períodos: o primeiro, classificado de período um (I), vai de fevereiro a abril e refere-se a todas as operações de sementeira da cultura do fumo; o segundo, periodo dois (II), inclui os meses de maio e junho, época em que se concentram as operações de preparo do solo (lambica gem e encanteiramentol e plantio; no terceiro periodo, trés (III), são executadas todas as operações de tratos culturais, 
compreendendo os meses de jutho e agosto, quando são executa das as operações de capinas, adubação, pulverização e desbrota; o quarto (IV) período, que vai de setembro a dezembro é considerado como um período em que se concentram as tarefas de colheitas das culturas. No caso da cultura da mandioca, os tratos culturais vão de jultho atē o mês de novembro.

0 modelo básico é formado por sete tipos diferentes de atividades de produção, compra de mão-de-obra em - quatro periodos, consumo familiar, trēs atividades de transferência e venda de produtos, cujos coeficientes tēcnicos se. encontram no Apēndice II. As exigências tēcnicas, bem fomo as disponibilidades dos recursos, foram calculadas levando-se em conta as médias dos valores observados na amostra.

\subsubsection{ATIVIDADES DE PRODUÇAOO}

As atividades produtivas que formarão o modelo foram selecionadas com base na frequéncia com que foram explo radas pelos agricultores da amostra no ano agrícola de 1983.

Assim; foram inciuidas aquelas combinações exploradas por pelo menos cinco agricultores. Os dados mostraram que $94 \%$ dos agricultores plantam fumo consorciado com outras culturas, sendo que o feijão aparece em $74 \%$ das propriedades, seguido do algodão (em $64 \%$ ), mandioca (em $60 \%$ ) e batatá, em 54\%. Os consōrcios mais encontrados foram: fumo/algo dão/fei.jão/batata $\left(x_{01}\right)$, fumo/algodão/feijão $\left(x_{02}\right)$, fumo/algo dão/batata $\left(x_{03}\right)$, fumo/feijão/mandioca $\left(x_{04}\right)$, fumo / algodão 
$\left(x_{05}\right)$, fumo / feijão $\left(x_{06}\right)$ e fumo / mandioca $\left(x_{07}\right)$. Os dados mostraram claramente que os produtores usam praticamente a mesma tecnologia de cultivo para todas as culturas consorciadas com o fumo. Isto pode ser meThor obsèrvado nos custos de produção correspondentes às atividades selecionadas, onde se identifica um sistema de produção. (Apêndice I). E possível que isto se deva ao fato de as culturas estarem sempre consorciadas com fumo, a principal at - vidade de produção, tanto em termos de ārea, como de produção.

A quantidade de mão-de-obra empregada, por hec tare, ē bastante expressiva, jā que não hā, por parte desses produtores, uso de força animal ou mecãnica no trato das culturas.

Como as épocas de plantio, tratos culturais e colheita são as mesmas para praticamente todas as atividades de produção consideradas, foi possivel estimar os custos de produção de cada atividade por períodos, o que, mais uma vez, vem reforçar a afirmativa de homogeneidade tecnológica adotada pelos agricultores.

4.2.2. ATIVIDADES DE CONTRATAÇAO DE MAO-DE-OBRA

E CREDITO

Essas atividades permitem que sejam contrata- 
das mão-de-obra permamente e temporária nos períodos I, II, III e IV a diferentes salārios. O maior salārio diārio é observado nos períodos III e IV, épocas referentes respectivamen te aos tratos culturais e coineita, refletindo uma maior demanda por este fator, em relação aos outros períodos.

A atividade de credito permite que o mesmo pos sa ser obtido nos períodos I, II e III à taxa de juro subsidiada de $35 \%$ a.a... Esta se tratava de uma linha especial de crédito dentro do programa POLONORDESTE (Programa de Desenvol vimento do Nordeste).

\subsubsection{ATIVIDADES DE TRANSFERENCIA}

Estas atividades permitem que qualquer exceden te de recursos financeiros (capital próprio e crédito) num pe ríodo, seja transferido para o perĩodo seguinte.

\subsubsection{ATIVIDADE DE VENDA DE PRODUTOS}

Estas atividades se referem à venda dos produtos comercializados dos consōrcios, quais sejam, fumo, feijão, algodão, mandioca e batata.

\subsubsection{ATIVIDADE DE CONSUMO}

Diante da informação de que a maioria dos produtores destina parte de sua produção de feijão, mandioca e 
batata para o consumo familiar, deduziu-se a quantidade consu mida das disponibilidades a serem empregadas à produção comer cial. Esse procedimento implica em assumir uma função de uti lidade lexicogrāfica por parte dos agricultores.

\subsubsection{ATIVIDADES DE COMPRA}

Estas atividades foram criadas para permitir ao agricultor opção de compra de feijão, batata e mandioca, Assim, o modelo bāsico inicialmente composto de 27 atividades, foi modificado, somando um total de 30 atividades.

Em suma, as atividades que compõem o modelo são:

$x_{01}=$ fumo/feijão/algodão/batata, plantados em junho, com colheita em agosto e setembro;

$x_{02}=$ fumo/aigodão/feijão, plantados tambēm em junho, com colheita prevista para os meses de agosto e setembro;

$x_{03}=$ fumo/algodão/batata, com plantios concen trados no més de junho, a colheita, è pa ra a maioria dos agricultores, realizada nos meses de agosto e setembro;

$x_{04}=$ fumo/feijão/mandioca, com plantios realizados em junho, para o fumo e feijão a colheita se dá nos meses de agosto e setembro, tendo a mandioca sua colheita feita basicamente no més de dezembro;

$x_{05}=$ fumo/algodão, plantados em junho, a coTheita $\vec{e}$ feita principalmente nos meses de agosto a setembro;

$x_{06}=$ fumo/feijão, plantados em junho, a colhei ta é feita principalmente nos meses de agosto e setembro; 


$$
\begin{aligned}
x_{07}= & \text { fumo/mandioca, com plantios realizados em } \\
& \text { junho, a colheita do fumo está concentra } \\
& \text { da no mês de agosto, ficando a mandioca } \\
& \text { para ser colhida em dezembro; } \\
x_{08} & \text {. } \\
x_{15}= & \text { contratação de mão-de-obra permanente e } \\
& \text { temporāria; respectivamente, durante os } \\
& \text { perĩodos I, II, III e IV; } \\
x_{16} \text { a } & \text { para o seguinte; } \\
x_{18}= & \text { transferência de capital de um perĩodo } \\
& x_{19}=\text { crēdito bancārio subsidiado; } \\
x_{20}= & \text { venda de fumo; } \\
x_{21}= & \text { consumo de feijão; } \\
x_{22}= & \text { venda de feijão; } \\
x_{23}= & \text { venda de algodão; } \\
x_{24}= & \text { consumo de batata; } \\
x_{25}= & \text { venda de batata; } \\
x_{26}= & \text { consumo de mandioca; } \\
x_{27}= & \text { venda de mandioca; } \\
x_{28}= & \text { compra de feijão; } \\
x_{29}= & \text { compra de batata; } \\
x_{30}= & \text { compra de mandioca. }
\end{aligned}
$$




\subsection{As RESTRI CÕES}

0 modelo básico consta de 26 restrições.

\subsubsection{TERRA}

Tentou-se identificar o uso das terras bem como as disponibilidades das āreas. Encontrou-se apenas um ūnico tipo de terra, definida pelos agricultores entrevistados, como sendo de fertilidade média. Como o universo pesquisado considerou tão somente os pequenos produtores, toda área dis: ponível está ocupada apenas com culturas. Em média, a disponibilidade de terra foi de 4,02 hectares.

\subsubsection{MAO-DE-OBRA}

Na amostra estudada, os agricultores em sua totalidade, não possuem e não alugam māquinas ou animais de trabalho para execução de qualquer operação agrĩcola, sendo todas as operações realizadas manualmente.

Nos anos normais de chuva, toda mão-de-obra fa miliar dispensa o trabalho fora da sua unidade de produção. Se gundo os proprietārios informantes, somente nos anos em que a seca ou excesso de chuva affetam significativamente a agricultura da região, essa mão-de-obra passa a prestar serviço fora da propriedade, mais especificamente nas frentes de trabalho criadas pelos Governos Federal, Estadual e Municipal com essa 
finalidade: Dados extraídos dos questionārios mostram que apenas alguns agricultores, em torno de $6 \%$, complementam suas rendas familiar trabalhando como funcionārios municipais ou possuindo pequenas ?ojas chamadas na região de "bodegas".

No cálculo das exigēncias da mão-de-obra, levou-se em consideração que a mão-de-obra feminina corresponde a $75 \%$ da masculina e a mão-de-obra do menor foi comparada a $50 \%$ da masculina.

A disponibilidade de mão-de-obra familiar, tem porāria e permanente representam na verdade, as quantidades empregadas daqueles recursos, no ano agrícola. Isto ocorreu devido à impossibilidade de se conseguir valores que refletis sem a verdadeira limitação da mão-de-obra a que estão sujeitos os agricultores.

\subsubsection{CAPITAL PROPRIO}

Observou-se que $78 \%$ dos agricultores utilizam capital próprio para suprir as necessidades financeiras de cus to operacional, não totalmente cobertas pelo crédito rural sub sidiado. Esse crédito é obtido principalmente nas agéncias do Banco do Brasil e do Banco do Nordeste. O montante de capital próprio disponivel corresponde ao valor médio obtido nos questionārios. 
33.

\subsubsection{CREDITO BANCARIO}

o crédito bancário concedido aos agricultores para o año de 1983, trata de uma linha especial de crédito dentro do programa do POLONORDESTE (Programa de Desenvolvimento do Nordeste), cuja taxa de juro era altamente subsidiada, ou seja, $35 \%$ ao ano, com inîcio da liberação em abril e prazo final de pagamento em janeiro.

0 crédito rural era (e continua sendo) liberado em três parcelas. A primeira é liberada em abril atendendo as operações de preparo do solo, plantio e corresponde aproximadamente $50 \%$ do total financiado. A segunda. parcela, liberada em junho e correspondente a $25 \%$ do montante financiado, visa atender aos gastos com tratos culturais: A terceira e ūtima parcela, aproximadamente $25 \%$ do financiamento, objetiva cobrir gastos com as operações de colheita, sendo liberada no mês de julho. Portanto, neste estudo, o crēdito concedido aos agricultores, enquadra-se perfeitamente nos períodos I, II, III e IV. Adotou-se como disponibilidade de crédito, o valor médio obtido nos questionārios.

As restrições de consumo de feijão, batata e mandioca representam parte da produção que os agricultores destinam para autoconsumo, o que significa que o agricuitor produz principalmente para o consumo e somente o restante da produção é destinada à venda. Como a maioria dos coeficien tes, o.valor adotado foi a quantidade média de consumo extraída dos questionārios, ou seja, $200 \mathrm{~kg}$ de feijão, $102 \mathrm{~kg}$ de batata e $391 \mathrm{~kg}$ de mandioca, por ano. 
Assim, as restrições que constam do modelo são:

$\mathrm{R}_{01}=$ teria

$R_{02}{ }^{a}$

$R_{13}=$ mäo-de-obra familiar, permanente e tempo rária, nos períodos I, II, III e IV, res pectivamente;

$R_{14}=$ capital prōprio no período I;

$R_{15} \mathrm{a}$

$R_{17}=$ parcela de crēdito para as culturas;

$R_{18}=1$ imite total de crédito;

$R_{19}$ a

$R_{23}=$ balanço de fumo, feijão, algodão, batata e mandioca.

$R_{24} \mathrm{a}$

$R_{26}=$ consumo de feijão, batata e mandioca. 


\section{CAPÍTULO 5}

\section{RESULTADOS E DISCUSSÃO}

\section{I. INTRODUGÃO}

Este capituio tem como objetivo apresentar e discutir os resultados dos modelos de programação linear com risco, construídos a partir das atividades e restrições descritas no capítulo anterior.

Primeiramente, é apresentado o modelo básico, que teve como objetivo reproduzir o processo de tomada de decisão dos agricultores da amostra. Em seguida, o modelo básico é modificado a fim de relaxar a restrição de consumo de ali mentos, considerada a mais limitante.

Todas as atividades de produção que compõem o modelo $\left(x_{1}\right.$ a $\left.x_{7}\right)$, foram consideradas geradoras de risco. Isto porque tanto as produtividades como os preços dos produtos não são conhecidos pelos produtores no momento da tomada de decisão. Os preços dos insumos foram considerados conhecidos pelos agricultores, embora se reconheça a existencia de um certo grau de incerteza quanto aos preços de certos recursos. 
A receita bruta esperada de cada consórcio de culturas foi calculada a partir das receitas brutas das culturas individuais, dos ūitimos cinco anos. Primeiramente, as sé ries de réceitas brutas nominais de cada cultura do consōrcio foram expressas em cruzeiros esperados de dezembro de 1983, se gundo expectativa de inflação obtida diretamente nas entrevistas com os agricultores da amostra. Em seguida, essas recejtas foram somadas, chegando-se à receita bruta recebida de cada consōrcio, em cada um dos ültimo cinco anos (Apēndice 1). Construída essa série, calculou-se a receita bruta esperada do consōrcio pela mēdia aritmētica das receitas brutas dos ūiti-. mos cinco anos.

Para o cālculo do risco de cada consörcio, deduziu-se a receita bruta recebida em cada ano, da receita média esperada, chegando-se assim, aos desvios em relação à média, como medida de risco. Para que fosse possível comparar o grau de risco dos consórcios individuais, dividiu-se o desvio médio absoluto pela receita esperada de cada um (Tabela2). os resultados mostraram uma grande variação no grau de risco dos consórcios, desde.coeficienté de variação igual a 3 para - consōrcio $x_{7}$, até $12,04 \%$ para o consórcio $x_{7}$.

Como se pode observar, os consórcios de maior risco não são necessariamente os que apresentam maior margem bruta por hectare. 0 consórcio $x_{3}$, por exemplo, possui o terceiro maior coeficiente de variação e a menor margem bruta por hectare. Por outro lado; o consōrcio $x_{4}$ possui baixo risco e a maior margem bruta. 
Tabela 2. Desvio absoluto mēdio, coeficiente de variação e mar gem bruta esperada de consórcios selecionados, pequenos fumicultores. Arapiraca, Alagoas, ano agríco1 a 1983.

\begin{tabular}{cccc}
\hline Consōrcio & $\begin{array}{c}\text { Desvio } \\
\text { absoluto } \\
\text { médio }\end{array}$ & $\begin{array}{c}\text { Coeficiente } \\
\text { de varia- } \\
\text { ção } \%)\end{array}$ & $\begin{array}{c}\text { Margem } \\
\text { bruta } \\
(\text { Cr\$/ha) }\end{array}$ \\
\hline$x_{7}$ & $40.807,60$ & 12,04 & $208.160,00$ \\
$X_{2}$ & $44.604,60$ & 11,71 & $265.978,00$ \\
$X_{3}$ & $24.387,80$ & 9,96 & $113.889,00$ \\
$X_{6}$ & $23.398,40$ & 8,61 & $138.619,00$ \\
$X_{5}$ & $16.982,00$ & 6,53 & $132.096,00$ \\
$X_{4}$ & $17.226,40$ & 3,94 & $272.415,00$ \\
$X_{1}$ & $7.419,44$ & 3,00 & $123.648,30$ \\
\hline
\end{tabular}

a/ Igual a (desvio absoluto médio/receita bruta esperada) x 100;

b/ Calculada pela diferença entre receita bruta e custo variável, exceto mão-de-obra.

Fonte: Dados da amostra.

\subsection{MODELO BASICO}

A partir das restrições, exigēncias é custos dos diversos fatores de produção, obteve-se o resultado da programação linear, sem risco, correspondente à maximização da função lucro l' sujeita às restrições definidas no caI/ Lucro, neste caso corresponde à diferença entre receita bruta esperada e custos variáveis, medindo, portanto lucro, o retorno à mão-de-obra fá miliar, à administração, à terra e ao capital. 
pítulo anterior. Esta solução corresponde ao ponto IX da fron teira eficiente que é o ponto de mais alto lucro e risco (Tabe 1 a 3$)$.

O segundo passo consistiu em expandir a matriz com a finalidade de incorporar o risco das atividades de produção. A função lucro passou a ser uma restrição, cujo valor foi parametrizado com a finalidade de gerar a fronteira eficiente, representada na Figura 2 .

os resultados mostraram que dos sete consórcios selecionados na amostra, apenas quatro $\left(x_{1}, x_{3}, x_{4}\right.$ e $\left.x_{6}\right)$ fizeram parte das combinações da fronteira eficiente (Tabela 3). Dos consōrcios não selecionados, $x_{2}$ e $x_{7}$ são os que apresentaram maiores coeficientes de variação, ou seja, 11,71 e $12,04 \%$, respectivamente, embora possuam altas margens brutas por hectare. 0 consórcio $x_{5}$, por sua vez, não contēm alimentos de subsisténcia (feijão, mandioca e batata), fator certamente importante na seleção dos consórcios, pelo modelo.

A medida que se parte do ponto I até o ponto VIII da fronteira eficiente, observa-se umà substituição dos consórcios $x_{3}$ e $x_{6}$, pelos consórcios $x_{1}$ e $x_{4}$, embora mais da metade da ārea cultivada no ponto VIII ainda esteja sendo alocada ao consórcio $x_{1}$, o qual apresentou o mais baixo coeficien. te de variação (Tabela 2).

No ponto de mais altos risco e lucro (IX), as āreas alocadas aos consórcios $x_{3}$ e $x_{4}$. se reduzem em favor do consórcio $x_{l}$, que passa a ocupar aproximadamente $57 \%$ da ārea total cultivada. 


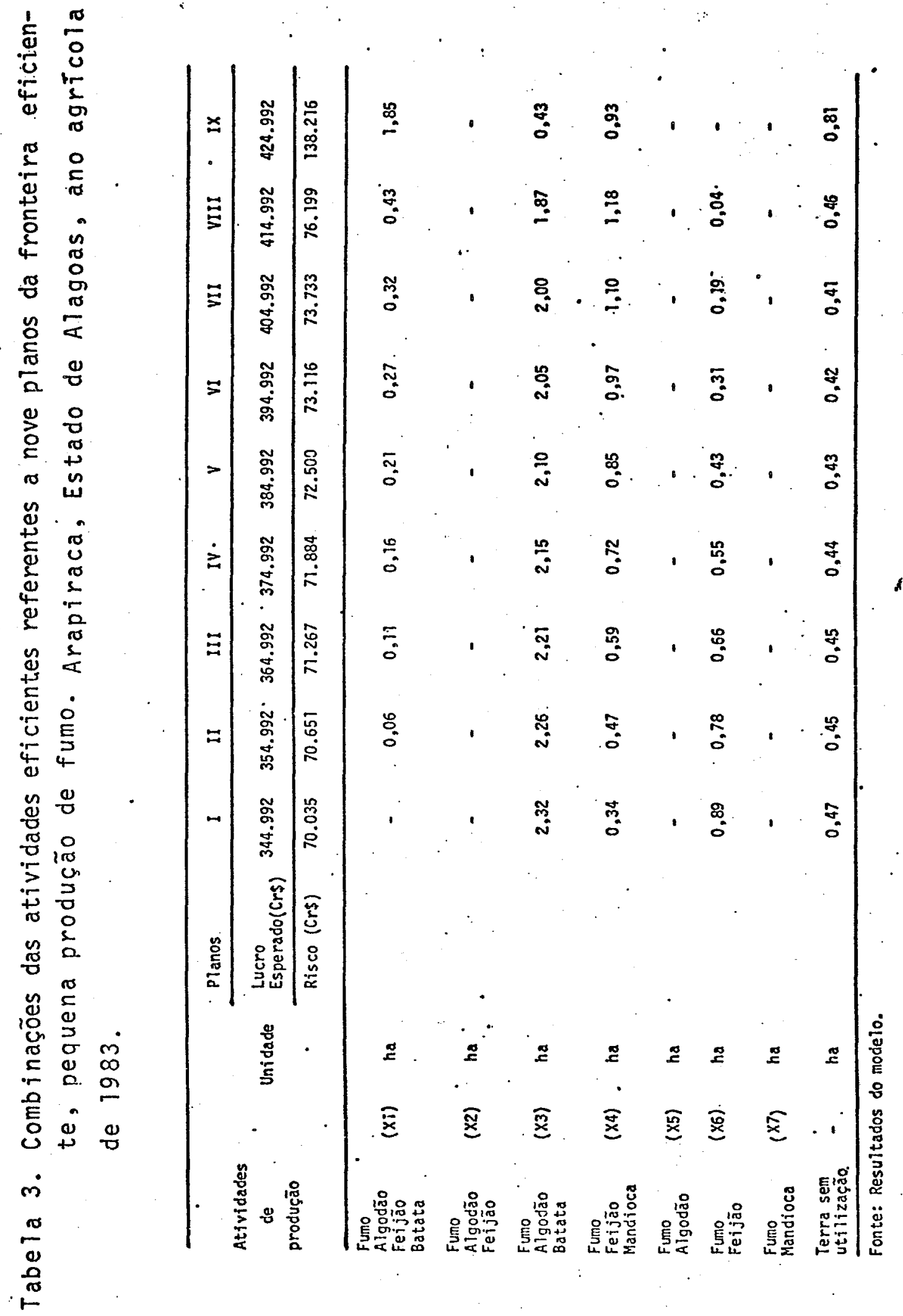




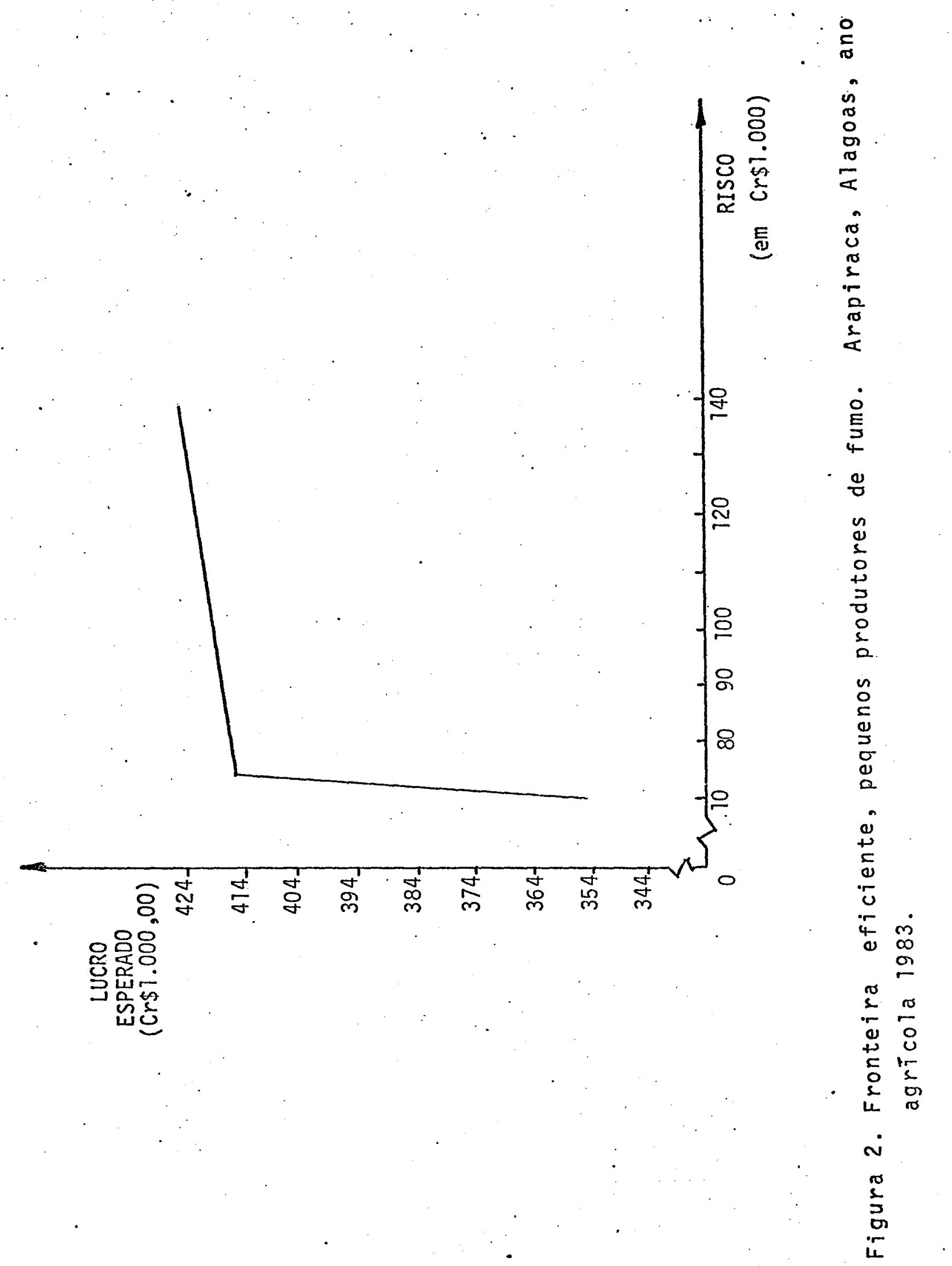


Em suma, a nîveis mais baixos de renda e ris co, há uma maior diversificação de consórcios, sendo $x_{3} 0$ consōrcio predominante em termos dé área cultivada, enquanto a nI veis altos de renda e risco, a diversificação é menor e a importáncia do consórcio $x_{1}$, maior.

Dessa maneira, ao considerarmos toda a fronteira eficiente, as atividades fumo/algodão/batata $\left(x_{3}\right)$ e fumol feijão/mandioca $\left(x_{4}\right)$, são sem dūvida, as mais importantes em termos de ārea cultivada, o que mostra uma boa aderēncia do mo delo à realidade, visto que estes dois consörcios são os que mais se repetem entre os agricuitores da amostra.

As mudanças ocorridas ao longo da fronteira eficiente, certamente implicaram em diferentes usos dos fatores de produção (Tabela 4). Por exemplo, em nenhum ponto da fronteira eficiente, a terra disponivel foi totalmente utilizada. De fato, exceto no ponto de māximo risco, a ārea não - cultiva da ficou entre 10 e $11 \%$ da ārea total disponivel.

A mão-de-obra familiar e permanente foram totalmente esgotadas em todos os periodos e para todos os planos da fronteira eficiente. 0 modelo foi estruturado de forma a permitir o uso de mão-de-obra permanente e temporária, somente depois de esgotada a mão-de-obra familiar de custo zero. As-. sim, também para a mão-de-obra temporāria, cujo custo é superior ao da mão-de-obra permanente, o modelo só permitiu o seu uso, depois de exaurida toda a disponibilidade de mão-de-obra familiar e permanente. 


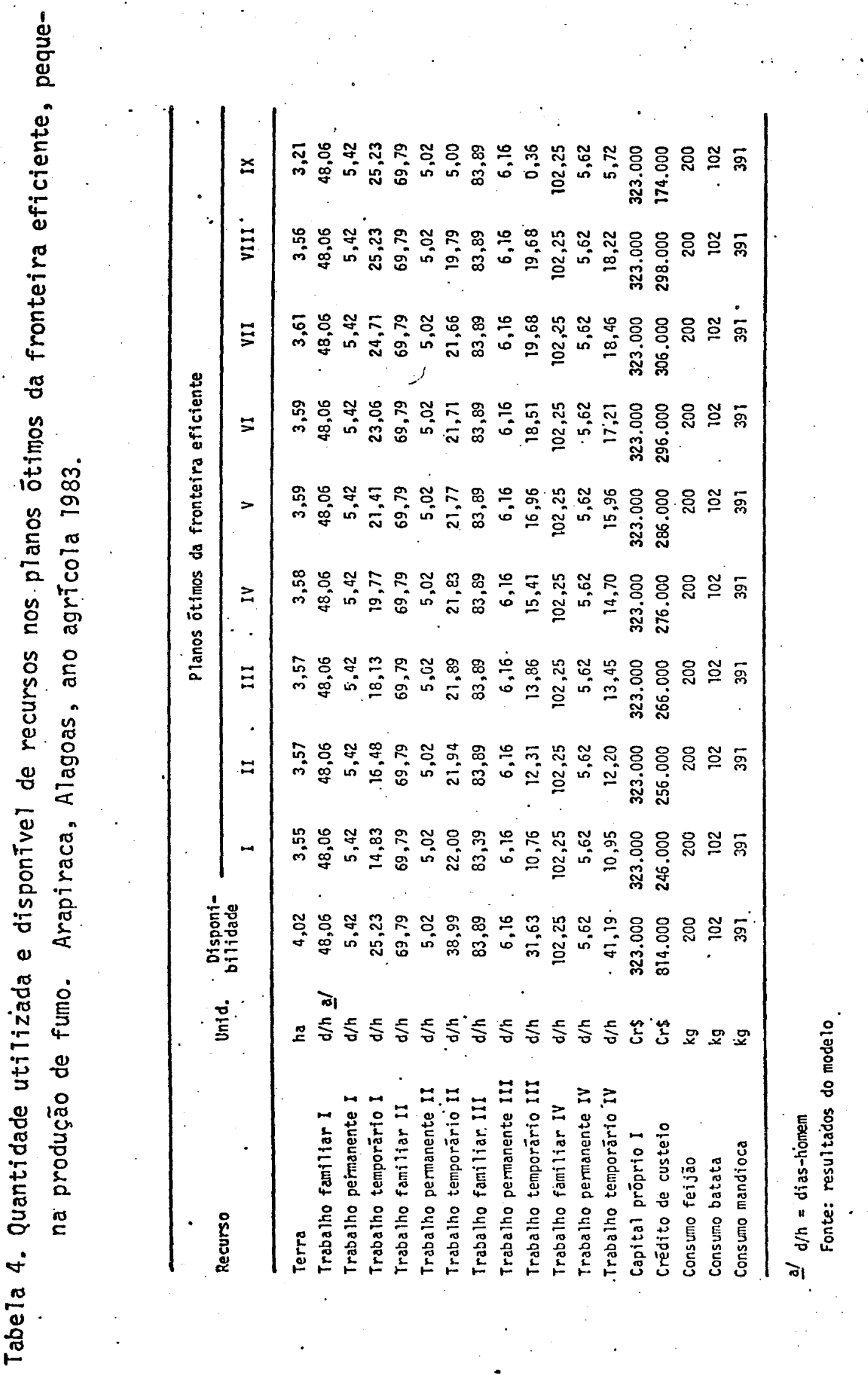


A grande exigēncia de mão-de-obra no periodo I, nas tarefas de sementeira, preparo do solo e limpeza do ter reno, ocupam toda a disponibilidade de mão-de-obra familiar permanente. A mão-de-obra temporāria, por sua vez tem seu uso crescente ao longo da fronteira, chegando ao seu limite disponível nos pontos VIII e IX.

Quanto aos periodos II, III e IV, a disponibilidade de mão-de-obra temporāria supera em muito as exigências das tarefas contidas em cada período. Como se pode notar na Tabela 4, as exigēncias de mão-de-obra temporária para estes períodos crescem à medida que aumentam os retornos $e$ os riscos, exceto para o plano de maior retorno e risco (ponto $I X)$, onde observa-se a mão-de-obra temporária sofrendo uma que da não apenas pelo aumento da área ociosa e diminuição da participação das atividades fumo/algodão/batata $\left(x_{3}\right)$, fumúffeijão /mandioca $\left(x_{4}\right)$ mas também pela ausência de fumo/feijão $\left(x_{6}\right)$, bastante intensiva no uso deste fator.

A Tabela 4 mostra ainda a disponibilidade de capital próprio e crēdito. Por exigencia do modelo, só de- pois de gasto todo capital próprio, começa o uso de crédito, o qual, em geral, se eleva com o aumento da renda e do risco, (com excessão do ponto de maior renda da fronteira IX), quando a quantidade de crédito utilizada, diminui. A causa disso, é a mesma que leva à redução da mão-de-obra temporāria nos perío dos II, III e IV, ou seja, a redução substancial na ārea cultivada das atividades fumo/algodão/batata $\left(x_{3}\right)$, fumo/feijão/man dioca $\left(x_{4}\right)$ e a ausēncia de fumo/algodão $\left(x_{5}\right)$, ben como o aumen 
to da ärea ociosa, os quais demandam uma quantidade menor de crèdito e mão-de-obra.

os resultados mostraram tambēm que em todos os pontos da fronteira eficiente; as quantidades consumidas de feijão, batata e mandioca foram iguais a 200,102 e $391 \mathrm{~kg}$, res pectivamente. Esses foram os niveis minimos de consumo impostos pelo modelo. Ou seja, para cada nível de lucro esperado, foi encontrada a combinação de consōrcios de menor risco que satisfez aqueles níveis de consumo.

Assim, de todas as restrições impostas pelo modelo, o consumo de alimentos pareceu ser o mais limitante de todos. Por esta razão, resolveu-se introduzir no modelo a opção de compra daqueles alimentos para satisfazer os niveis de consumo encontrados na amostra.

\subsection{MODELO COM RESTRIGÃO DE CONSUMO MODIFICADA}

Neste modelo, o consumo de alimentos pode ser satisfeito de duas maneiras: através da produção prōpria, como no modelo anterior, ou através da compra daqueles alimentos.

Os resultados encontrados foram bastante dife-. rentes dos anteriores, a começar pela quantidade ociosa de terra que passou a ser bem maior, ou seja, de 21 a $39 \%$ da terra disponivel, do ponto de maior para.o ponto de menor lucro esperado (Tabela 5 ). 


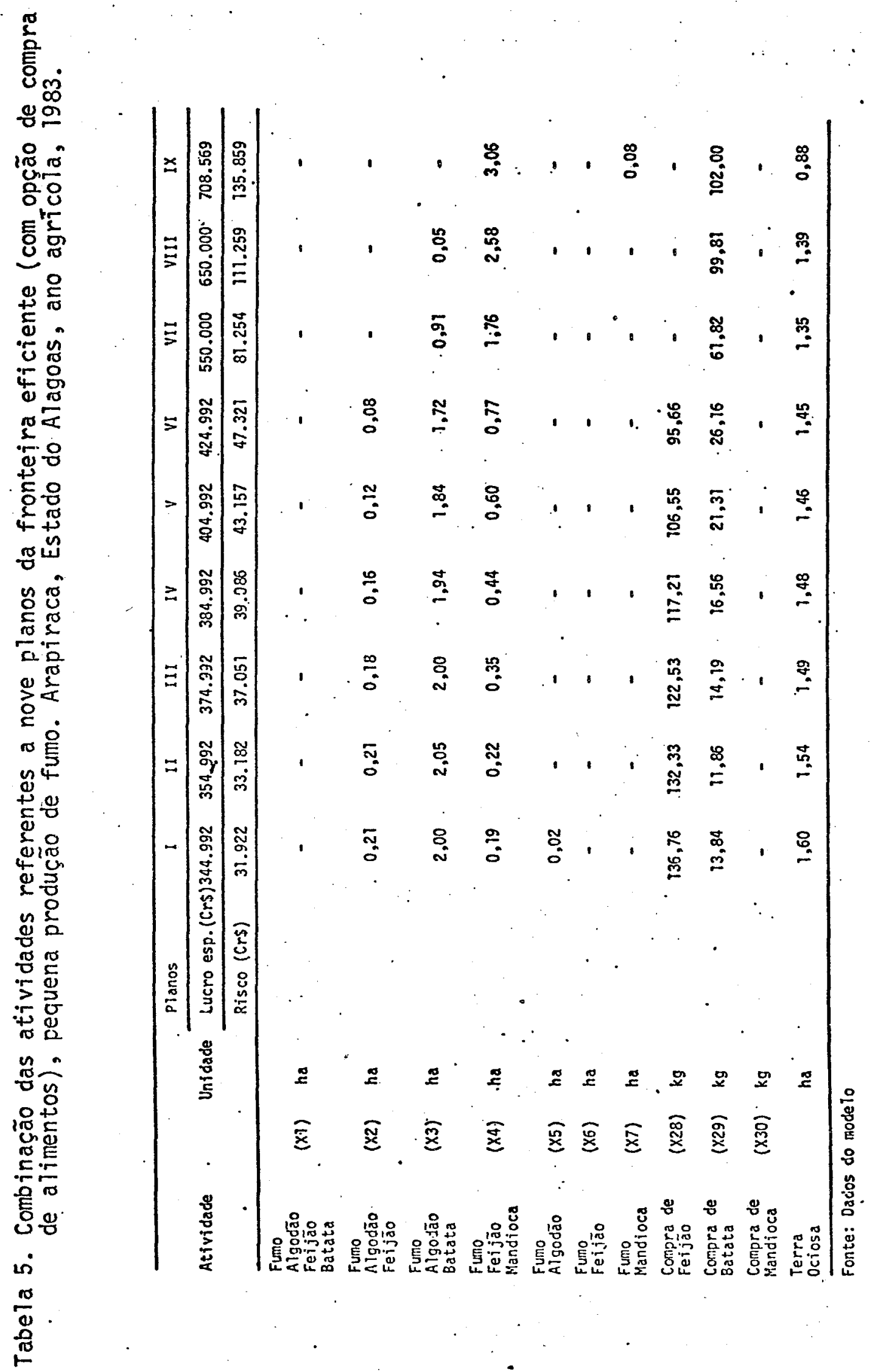


Os consórcios $x_{1}$ e $x_{6}$, que participaram de qua se todas as combinações de consōrcios do primeiro mọdelo, não foram selecionados em nenhum ponto da fronteira eficiente. Por outro lado, $x_{2}$, ausente na fronteira eficiente do modelo anterior, passa a participar dos planos até o nível de lucro esperado correspondente a nivel mais alto do modelo anterior, ou seja, 424.992 cruzeiros. E interessante lembrar que este con sórcio apresentou os segundos maiores graus de risco e margem bruta esperada.

Os consörcios $x_{5}$ e $x_{7}$, que não foram seleciona dos no primeiro modelo, só participaram de dois planos da fron teira $\left(X_{5}\right.$ no plano $I$ e $X_{7}$ no $\left.p l a n o ~ I X\right)$, ocupando respectivamen te, 0,8 e $2,5 \%$ da ārea total cultivada em cada um dos planos.

Do ponto de mais baixos lucro esperado e risco, até o ponto VI da fronteira eficiente, os consórcios $x_{2}$, $x_{3}$ e $x_{5}$ têm participações na ārea total cultivada, reduzidas, em favor do consórcio $x_{4}$. Até este ponto, a parte da quantida de consumida de feijão, comprada diminui, desaparecendo des te ponto em diante.

Do ponto VII até o ponto IX, $X_{2}$ não mais faz parte dos $p l a n o s$ da fronteira, e $x_{4}$ continua.se expandindo em detrimento de $x_{3}$, cuja ārea se torna nula no ponto IX, de mais altos lucro e risco.

Estas mudanças na composição dos planos são acompanhadas de um aumento da proporção consumida de batata, proveniente de compra. 
Ao contrārio do que ocorreu com feijão e batata, não houve compra de mandioca em nenhum ponto da. fronteira eficiente, o que significa que todo o consumo foi provenien te da própria produção da empresia.

o resultado mais importante desta simulação foi a obtenção de planos com menores graus de risco, a níveis de lucro esperado iguais aos do modelo anterior. Por exemplo, ao nível de lucro de $\operatorname{Cr} \$ 384.992,00$, os desvios são iguais a Cr $\$ 72.500,00$ e Cr $\$ 39.086,00$, respectivamente no primeiro e segundo modelos. Isto significa que a nova fronteira se encontra acima da fronteira eficiente gerada pelo modelo anterior (Figura 3). De fato, o nível de lucro esperado mais alto (ponto IX) é mais de 1,5 vezes maior nesta fronteira do que na fronteira gerada no primeiro modelo e quase $100 \%$ da área culti vada é alocada ao consórcio $x_{4}$, o que se tornou possivel com a compra de toda a quantidade consumida de batata naquele ponto.

Estes resultados certamente implicaram em padrões de uso dos recursos produtivos, diferentes daqueles encontrados no primeiro modelo (Tabela. 6).

0 uso de mão-de-obra é bem menor do que no prí meiro modelo. As quantidades de mão-de-obra utilizadas em todos os períodos só se igualaram às quantidades disponíveis em alguns pontos da fronteira.

De fato, em alguns casos, as quantidades utili zadas de mão-de-obra permanente e temporāria, foram nulas, como ocorreu no periodo IV, en todos os pontos da fronteira. 


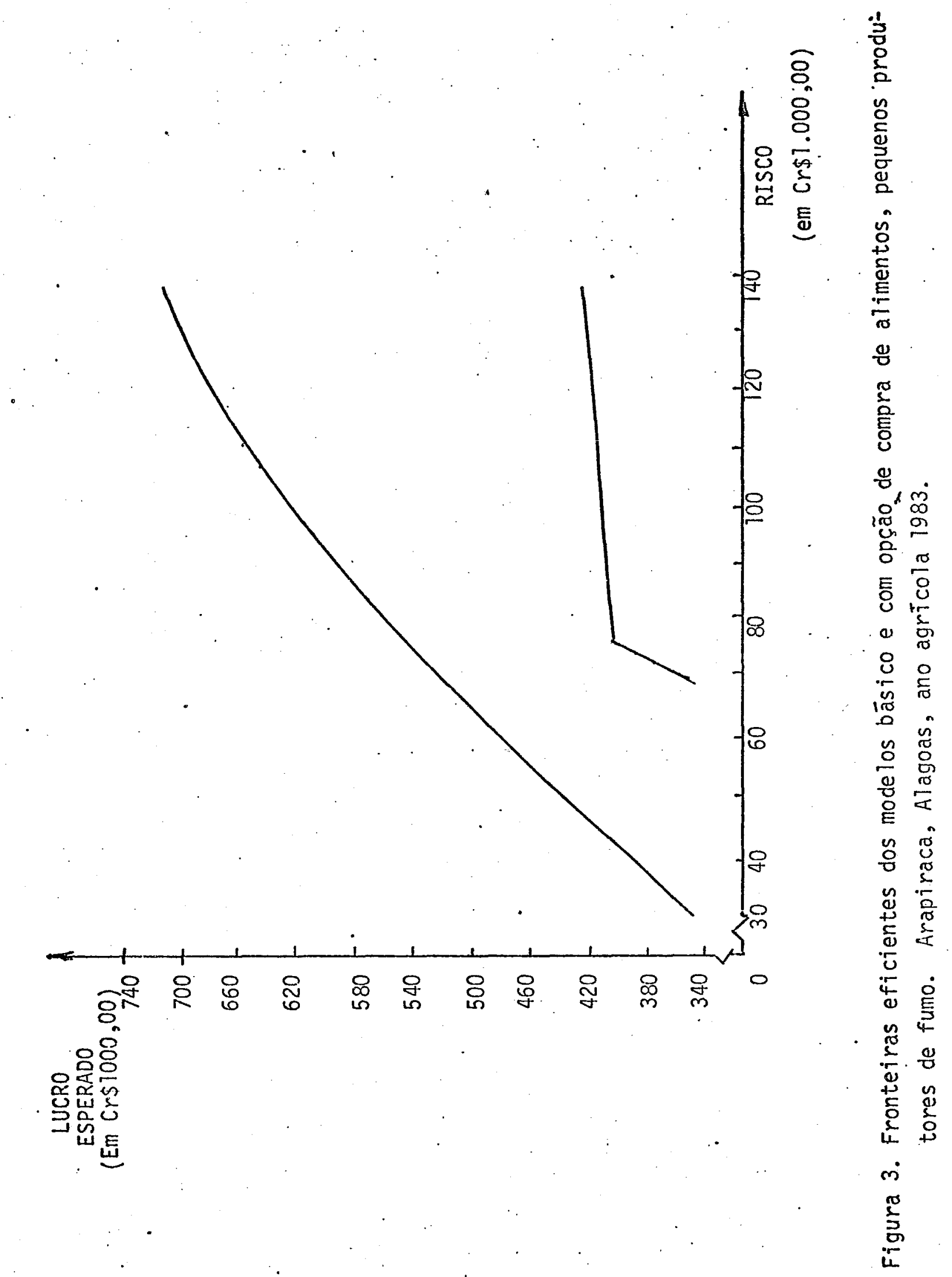




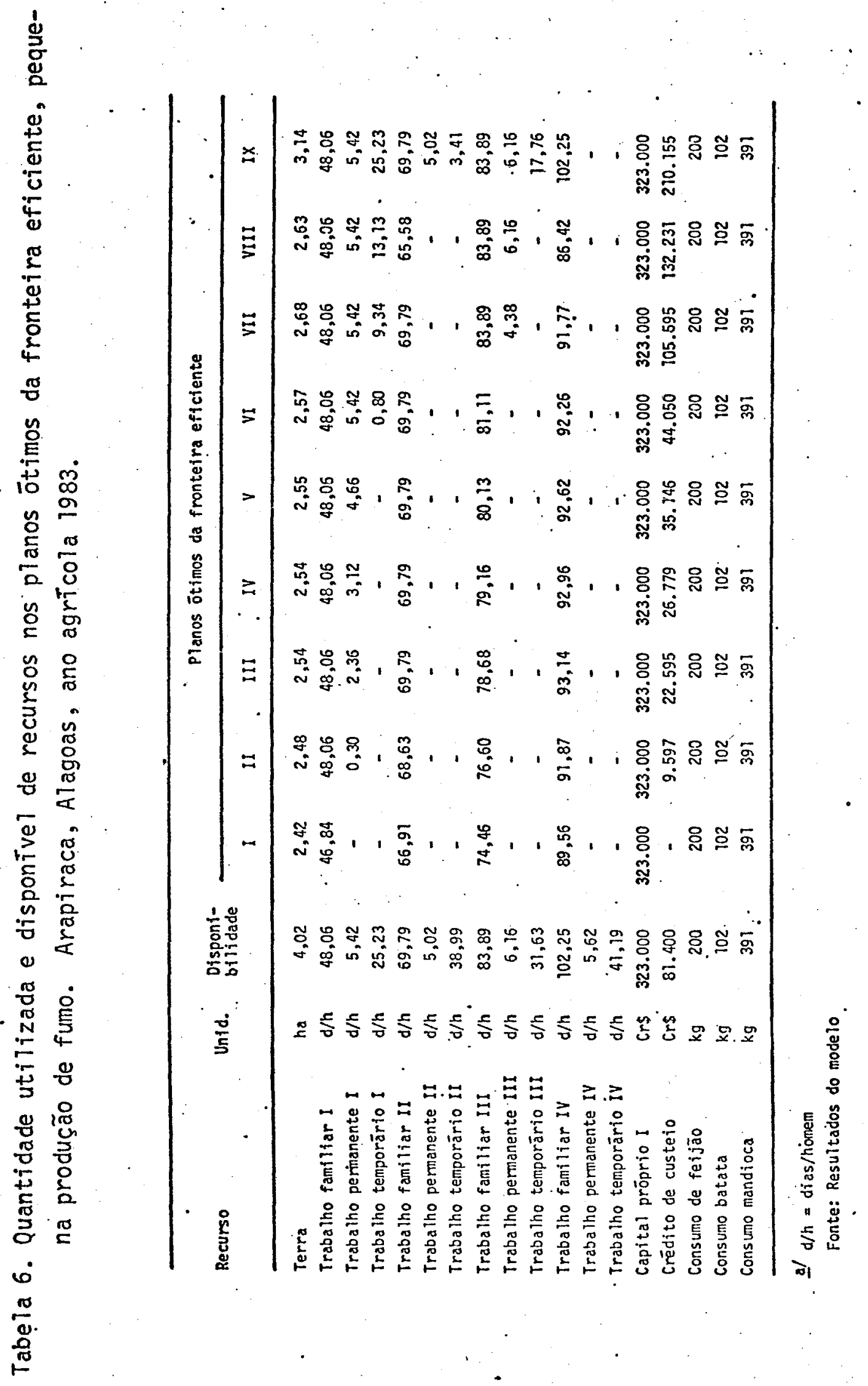


Também a utilização de crēdito de custeio foi bem menor neste modelo do que no anterior, o que pode ser explicado pelo decréscimo da área total cultivada em todos os planos da fronteira eficiente, em relação a primeiro modelo. 
51.

\section{CAPÍTULO 6}

\section{CONCLUSÕES E RECOMENDACÕES}

o objetivo principal deste estudo foi tentar reproduzir o processo de tomada de decisão de uma amostra de pequenos fumicultores de Arapiraca, no Estado de Alagoas, atra vés de um modelo de programação linear incorporando risco. A partir deste modelo, o estudo se propôs a identificar quais os recursos produtivos mais limitantes.e a investigar o efeitoque uma maior disponibilidade dos mesmos, teria sobre a renda esperada e o risco das diversas combinações de atividades produtivas.

os resultados mostraram uma boa aderéncia do modelo à realidade no tocante às combinações mais importantes nos diversos pontos da fronteira eficiente. Assim, as combinações mais importantes da fronteira foram $x_{1}$ (fumo/algodão/fei jão/batata) e $x_{3}$ (fumo/algodão/batata), sendo a primeira de baixos e a ūtima de altos risco e margem bruta e por ültimo, $x_{4}$, fonte de suprimento de mandioca para consumo, de baixos ris co e margem bruta. 
Entretanto, o uso da mão-de-obra (principalmen te temporáriab do crédito e da terra foram menores do que aque las encontradas na amostra. Dessa maneira, nenhum desses recursos foi limitante no modelo.

Todo o consumo de feijão, batata e mándioca, veio da produção desses alimentos, por construção do modelo, uma vez que este fato ocorre na realidade.

Dessa maneira, a seleção de consórcios nos diversos pontos da fronteira ficou limitada, em grande parte, às restrições de consumo mīnimo dos alimentos; impostas pelo mode 10. Por esta razão, decide-se modificar essas restrições, introduzindo no modelo a opção de compra dos alimentos. Assim, o consumo mĩnimo poderia ser atingido via compra ou produção daqueles alimentos.

Os resultados dessa simulação foram bastánte diferentes dos anteriores. Por exemplo, o nível de lucro do nonto correspondente à solução de programação linear sem risco, foi 1,5 vezes maior do que o do primeiro modelo.

0 consōrcio $x_{1}$ (fumo/algodão/feijão/batata) não fez parte de nenhum plano da nova fronteira eficiente. Por outro lado, o consōrcio $x_{2}$, nunca antes selecionado, participou de seis pontos da fronteira.

Grande parte da quantidade minima consumida de feijão é comprada a níveis mais baixos, de rénda e risco e à medida que crescem o lucro e o risco, cresce também a quantida de comprada de batata destinada ao consunio, a qual se iguala ao total consumido no ponto IX da fronteira. A opção de com- 
pra deste alimento permitiu ao modelo substituir $x_{3}$, que possui batata; por $x_{4}$ que não possui aquele alimento.

Em nenhum ponto da fronteira eficiente houve compra de mandioca, o que significa que toda a quantidade consumida deste alimento foi produzida na propriedade.

As quantidades utilizadas de terra, mão-de-obra e crédito de custeio foram ainda menores neste modelo, quando comparadas ao primeiro.

A introdução das op̧̧ões de compra de alimentos permitiu, aos mesmos níveis de lucro esperado, a seleção de consórcios de menores graus de risco. Este é um resultado importante, uma vez que se acredita que a produção de alimentos tenha como objetivo principal a redução do risco. Isto rão quer dizer, certamente, que tal fenómeno não ocorra, pois, mes mo se introduzindo a onção de compra, a quantidade consumida de mandioca, em todos os pontos da fronteira eficiente, vem da produção, assim como acontece com o feijão nos pontos de maiores níveis de lucro.

Em suma, os resultados deste estudo indicam que combinações de consōrcios com menores graus de risco poderiam ser obtidas se os fumicultores da amostra comprassem parte das quantidades consumidas de feijão e batata, em todos os níveis de lucro esperados do modelo básico.

Estudos seme Thantes deveriam ser conduzidos com outros grupos de pequenos produtores (utilizando outras medidas de risco, inclusive) do Estado de Alagoas e outras regiões do país pois o conhecimento de alternativas que resul- 
tem em menores riscos, aos mesmos niveis de lucro esperados pa ra pequenos produtores é de extrema importāncia para o desenvolvimento desses grupos de agricultores. 


\section{Literatura Citada}

BARBOSA, C. Sebastião. Combinação de Exploração e Rentabilidade de Pequenos Estabelecimentos Agropecuārios do Município de Viçosa, Minas Gerais, 71/72. Tese de Mestrado, 1972. Universidade Federal de Viçosa. Viçosa, $M G$.

CEPA. Comissão. de Planejamento Agricola. Características da Região Fumageira, Estado de Alagoas, 1980.

DILLON, J.L. \& SCANDIZO, P.L. Atitudes dos Agricuttores de Subsistēncia Nordestina em Relação ao Risco. Abordagem Amostra1. Série Pesquisa, nọ 17. Departamento de Economia, Centro de Ciēncias Agrārias, UFC. Fortaleza-CE. 1976.

DILLON, J.L. \& MESQUITA, T.C. Atitudes de Pequenos Agriculto res do Sertão do Ceará Diante do Rịsco. Série Pesquisa, no 12. Departamento de Economia Agrícola, Centro de Ciēncias Agrārias, UFC. Fortaleza, CE. 1976.

DILLON, J.L. \& ANDERSON, J.R. Allocative Efficienty Tradicio nal Agriculture and Risk. American Journal of Agriculture, 53: 28-32. 1971 .

DILLON, J.L. \& ANDERSON, J.R. Agricultural Decisions Analysis. The Iowa University Press. Anis, Iowa, 7-101. 1977. 
DUARTE, P.A. Anālise Económica da Cuttura Pura e Consorciada do Feijoeiro sob Condição de Risco. Tese de Mestrado. Departamento de Economia Agrícola, Centro de Ciências Agrā rias, UFC, 1975. Fortaleza, CE.

ENGLER, Joaquim J.C. Anālise da Produtividade de Recursos na Agricultura. Tese de Doutorado, Escola Superior de Agricultura "Luiz de Queiroz"/USP. 1971. Piracicaba, SP.

ENGLER, Joaquim J.C. Alternative Enterprise Combinations Under Various Price Policies on wheat and Cattle Farms in Southern Brasil. Tese de Ph.D. Department of Agricultural Economics and Rural Sociology the Ohio State University. 1968.

FIBGE, Fundação Instituto Brasileiro de Geografia e Estatistica. Censo Agropecuārio de Alagoas, 1980.

FONSECA, V.0. Anālise Económica da Aplicação de Doses e Fontés de Nitrogênio na Cultura do Trigo, sob condições de ris co. Tese de Mestrado, Universidade Federal do Rio Grande do Sul, 1976. Pelotas, RS. 20-40.

HAZELL, P.B.R. A Linear Alternative to Quadratic and Semivariance Programing for Farm Planing under uncertainty. American Journal of Agricultural Economics, 53(1): 53-62. 1971.

HAZELL, P.B.R. \& SCANDIZZO, P.L. Optimal Price Intervention Policies when Production is Risky. Development Research Center, World Bank, Washington, 1974. Mimeografado.

HAZELL, P.B.R. A. Linear Alternative to Quadratic and Semivariance Programing in Farm Phamong under Uncertainty. Jour nal of Agricultural Economics, 53: 44-235. 1974. 
HEYER, J. An Analysis of Peasant Farm Production under condi tions of Uncertainty. Journal of Agricultural Economics, 23: 135-145. 1979 .

HOMEM DE MELO, F.B. \& CANTON, A.W.P. Risco na Agricultura Brą sileira: Nordeste versus Sul. Trabalho para Discussão no 37, Faculdade de Economia e Administração. Instituto de Pesquisas Econômicas, USP. São Pauto, 6: 10-25. 1980.

HOPKINS, J.A. Administração Rural. Editora Atlanta S.A. 27 a Edição. México, 210-290. 1952.

JUNQUEIRA, Antōnio A.B. Anālise Econōmica de uma Função de Produção de Fumo em Ubā, Estado de Minas Gerais, 1961. Série Ciência, Boletim nọ 4, 1961. Instituto de Economia Rural, Universidade Federal de Viçosa. Viçosa, Minas Gerais.

KUTELLER, G.P. \& SCANDIZZO, P.L. The Northeast Brasil Effort: A Progress Raport. Development Research Center, World Banc Washington, 1976. Mimeografado. 50-60.

LIPTON, M. The Theory of the Optimizing Peasant. Journal of Development Studies, 4: 327-351. 1968.

LoW, A.R.C. Decision Making under Uncertainty: A Linear Programing Model of Peasant Parmer Behavior. Journal of Agricultural Economics, 25: 22-311. 1974.

MARKOWITZ, H.M. Portfolio Selection. The Journal of Finance, I (1): 77-91. 1952 . 
58 .

MoUtinho, D.A. Escolha de Nova Tecnologia Sob Condições de Risco: O Caso do Feijão de Corda em Quixadā, Fortaleza. Tese de Mestrado. Departamento de Economia, Centro de Ciências Agrārias. Universidade Federal do Ceará, 1977. Fortaleza, CE.

NEVES, Evaristo Marzabal. Alocação de Recursos e Combinação de Atividades pela Programação Linear em Empresas Leiteiras na Região de Lins, Estado de São Paulo. Tese de Mestrado. Curso de Economia Rural, Universidade Federal de Viçosa, 1972. Viçosa, MG. 105p.

PASCALI, A.J. \& MOTA, P.S. Aspectos Bioclimäticos da Cultura do Trigo no Rio Grande do Sul. Pesquisa Agropecuāria Brasileira, I: 123-140. 1966.

PASTORE, J. Decisão em Condições de Incerteza na Agricuttura. Revista de Economia Rural, 1: 65-81. 1975.

PIRES \& PERES, A.R: Baixa Produtividade do Mitho como Consequência da Tomada de Decisão sob Condições de Risco na Agri cultura. Tese de Mestrado. Departamento de Economia e So ciologia Rural, ESALQ/USP, 1981. Piracicaba, SP.

SANDERS, J.A. \& HOLANDA, A.S. Designing New Technology for Small Farms: A Case Study in a Semi-arid area of the BrasilianNortheast. Department of Agriculture Economics, Federal University of Cearā, 1975. Mimeografado, 10-25.

SOARES, A.C.M. \& MEYER, R.L. Alocação de Recursos e Escolha de Atividades sob condições de Risco em Fazendas Cotonicul toras do Nordeste Semi-ärido. Revista de Economia Rural, 17(2): $95-129 . \quad 1979$. 
SUDENE. Scperintendéncia do Desenvolvimento do Nordeste. Pro posições da Politica Social para o Nordeste. Recife, PE, 1963.

TEIXEIRA FILHo, Antōnio R. Anālise da Produtividade Marginal dos Recursos Agrícolas em dois Municipios do Estado de Minas Gerais - Ituiabā e Caratinga. Ano Agrícola 1961/ 62. Tese de Mestrado. Universidade Rural de Minas Gerais, 1962. Viçosa, MG.

TOLINI, Hélio. Produtividade Marginàl e Uso dos Recursos. Anā lise da Função da Produção de L.eite em Leopoldina, Minas Gerais. Ano Agrícola 1961/62. Tese de Mestrado. Universi dade Rural do Estado de Minas Gerais. Viçosa, MG, 1962.

VEIGA, Alberto. Use and Productivity of Agriculture Resources. Jaguariuna County, São Paulo, Brasil. Tese de Mestra do. Lafayette: Purdue University. 165.

WIENS, T.B. Peasant Risky Aversion and Allocative Behavior: A Programming Experiment. University of Oregon Working Paper in Economics, 1974. 135-150. 


$$
\text { A } \underline{\underline{E}} \underline{N} \underline{D} \underline{C} \underline{E}
$$


61.

- Apêndice 1 


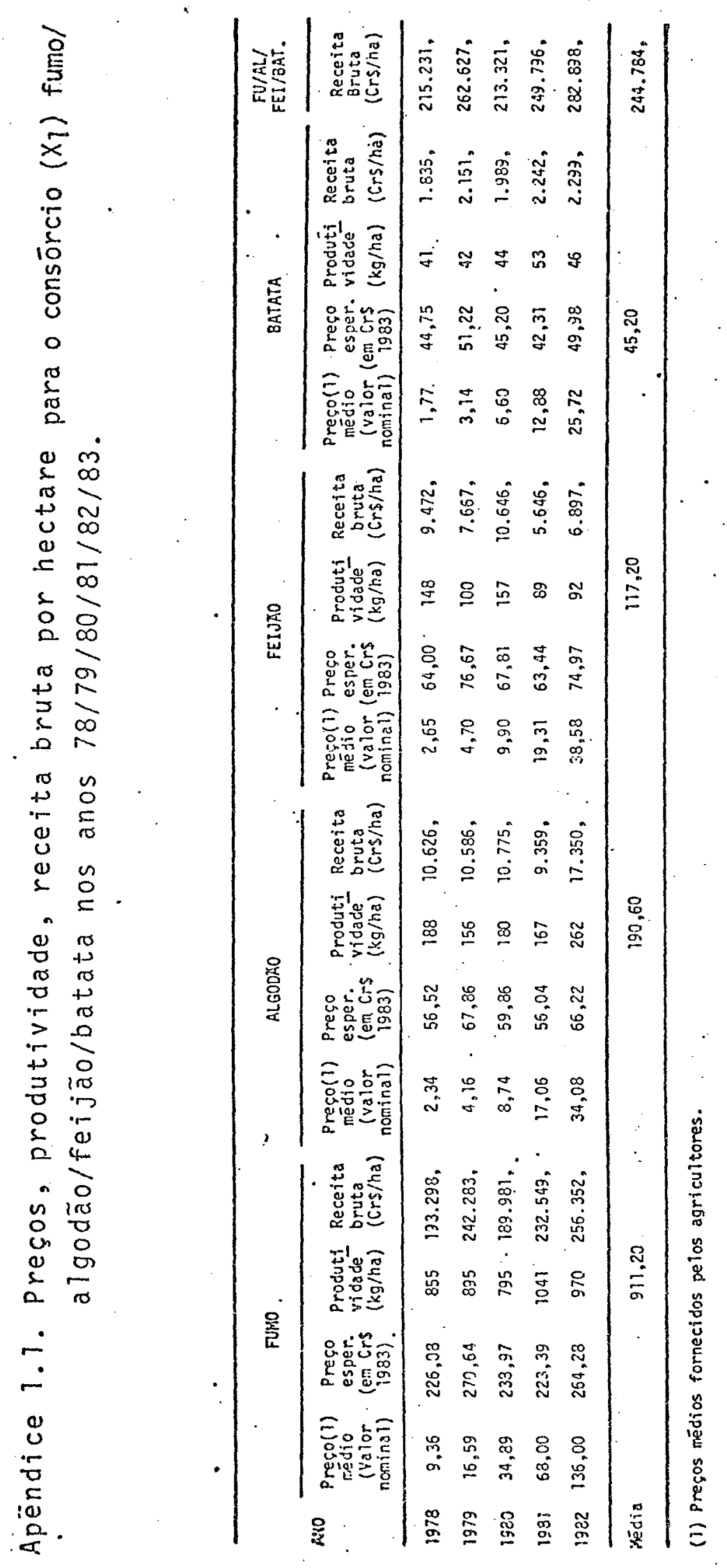




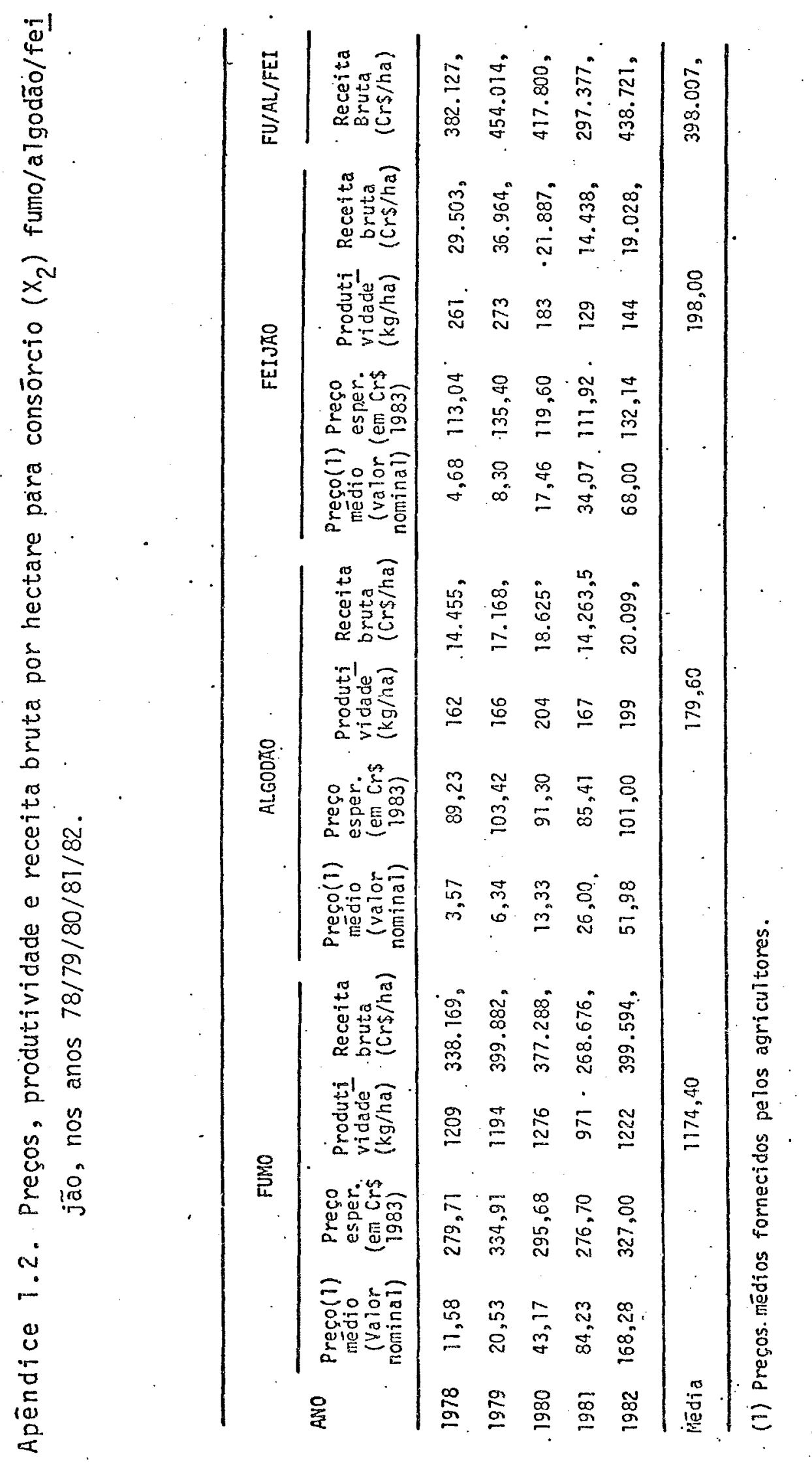




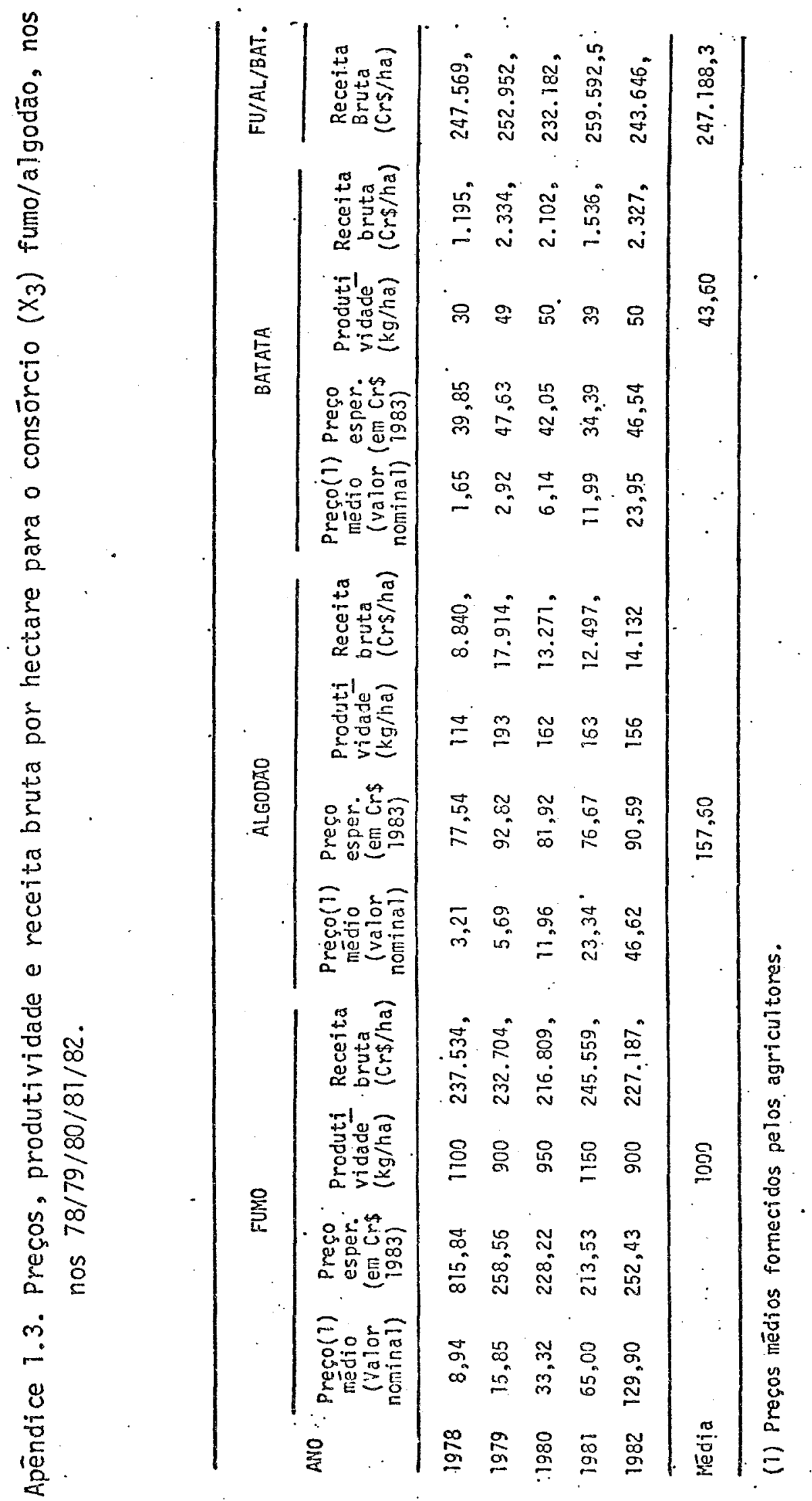




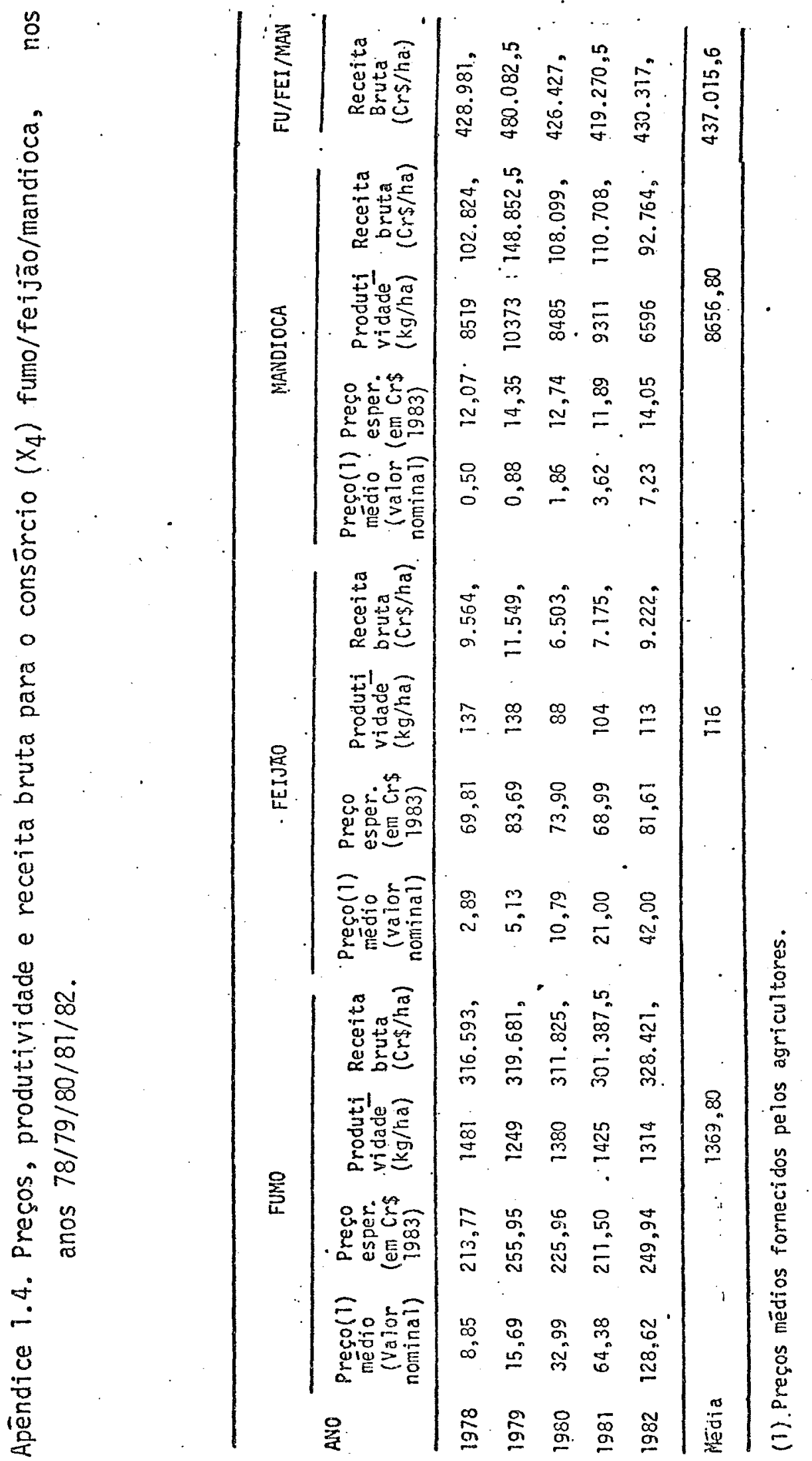




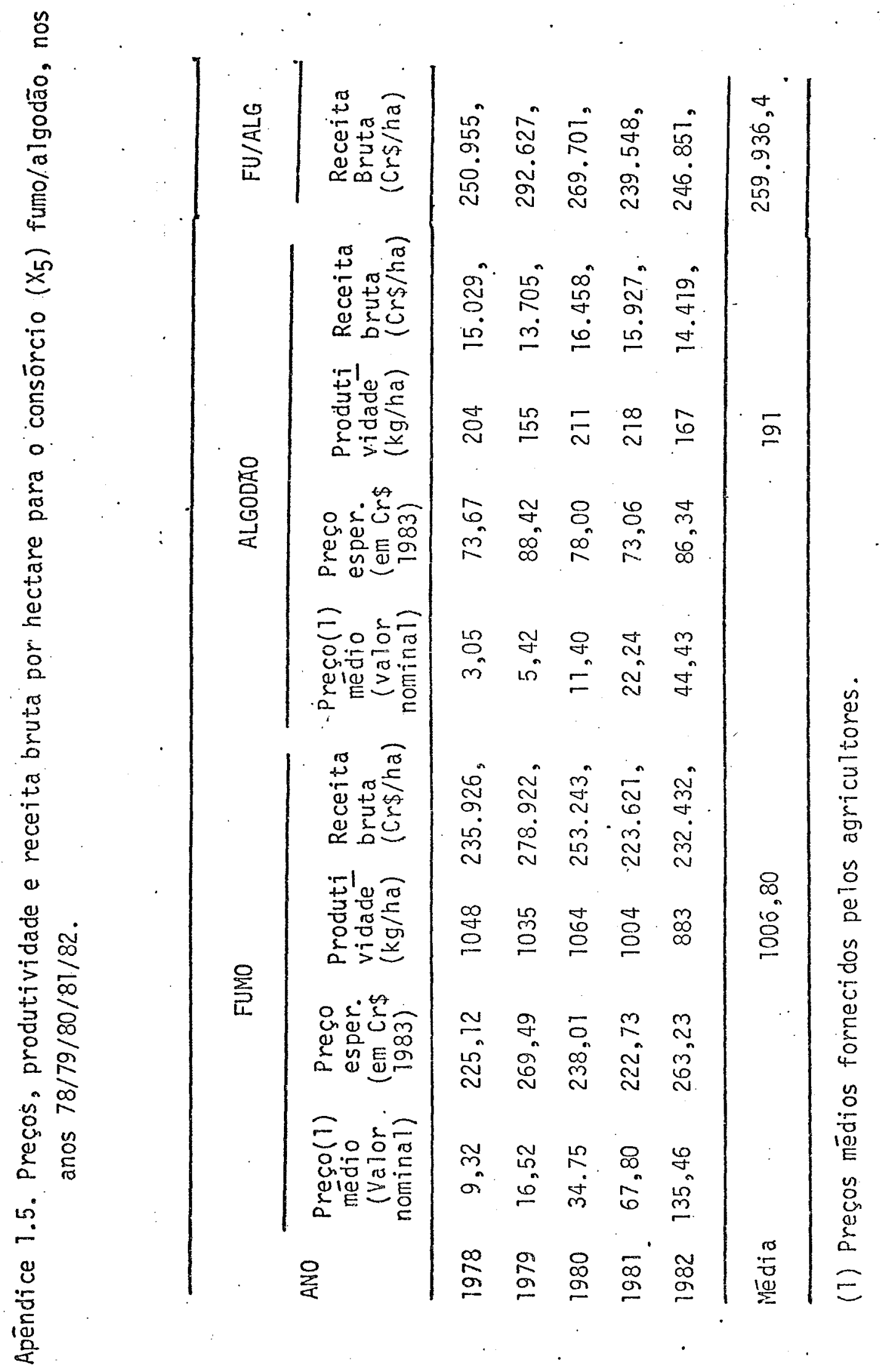




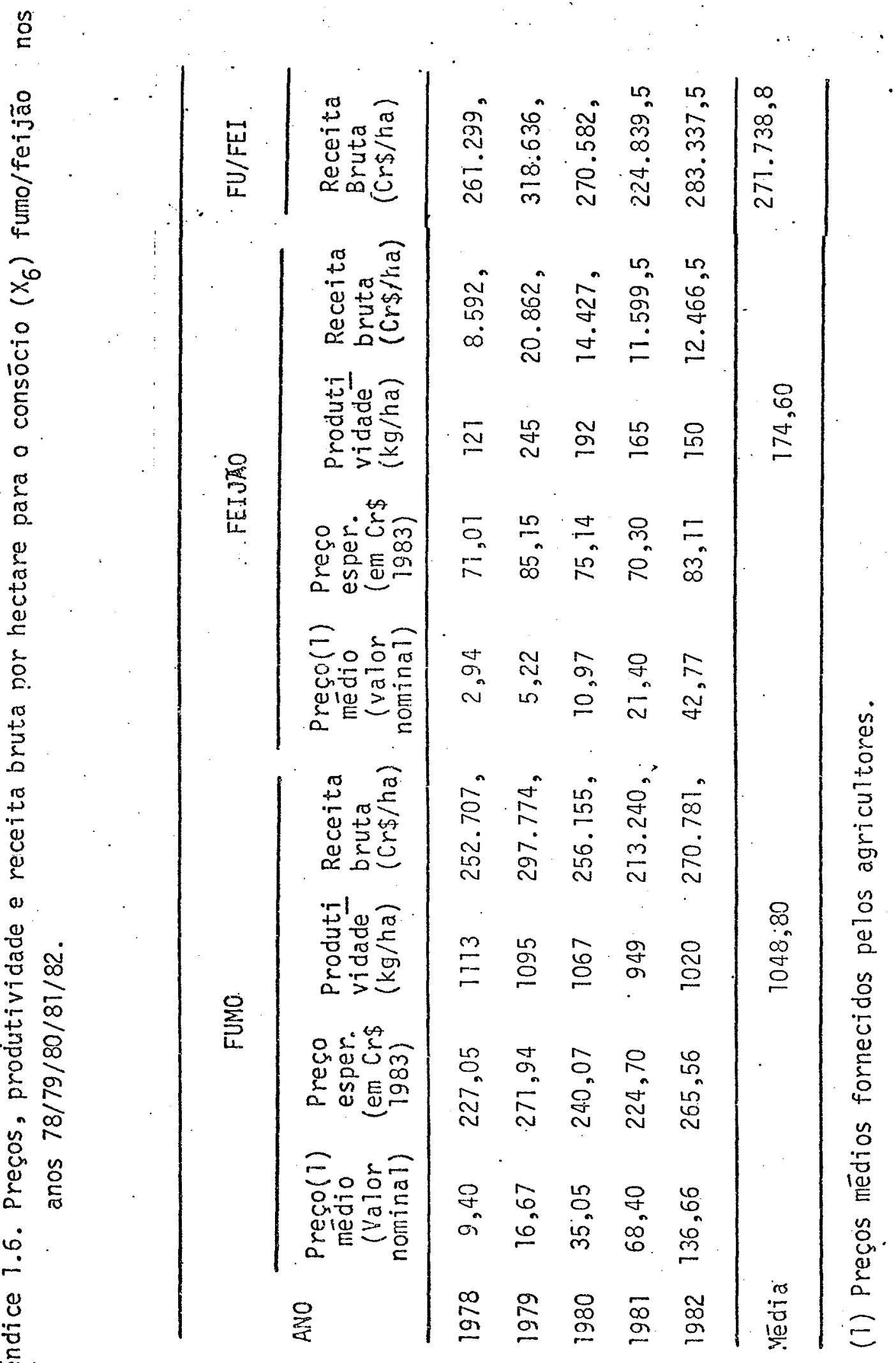




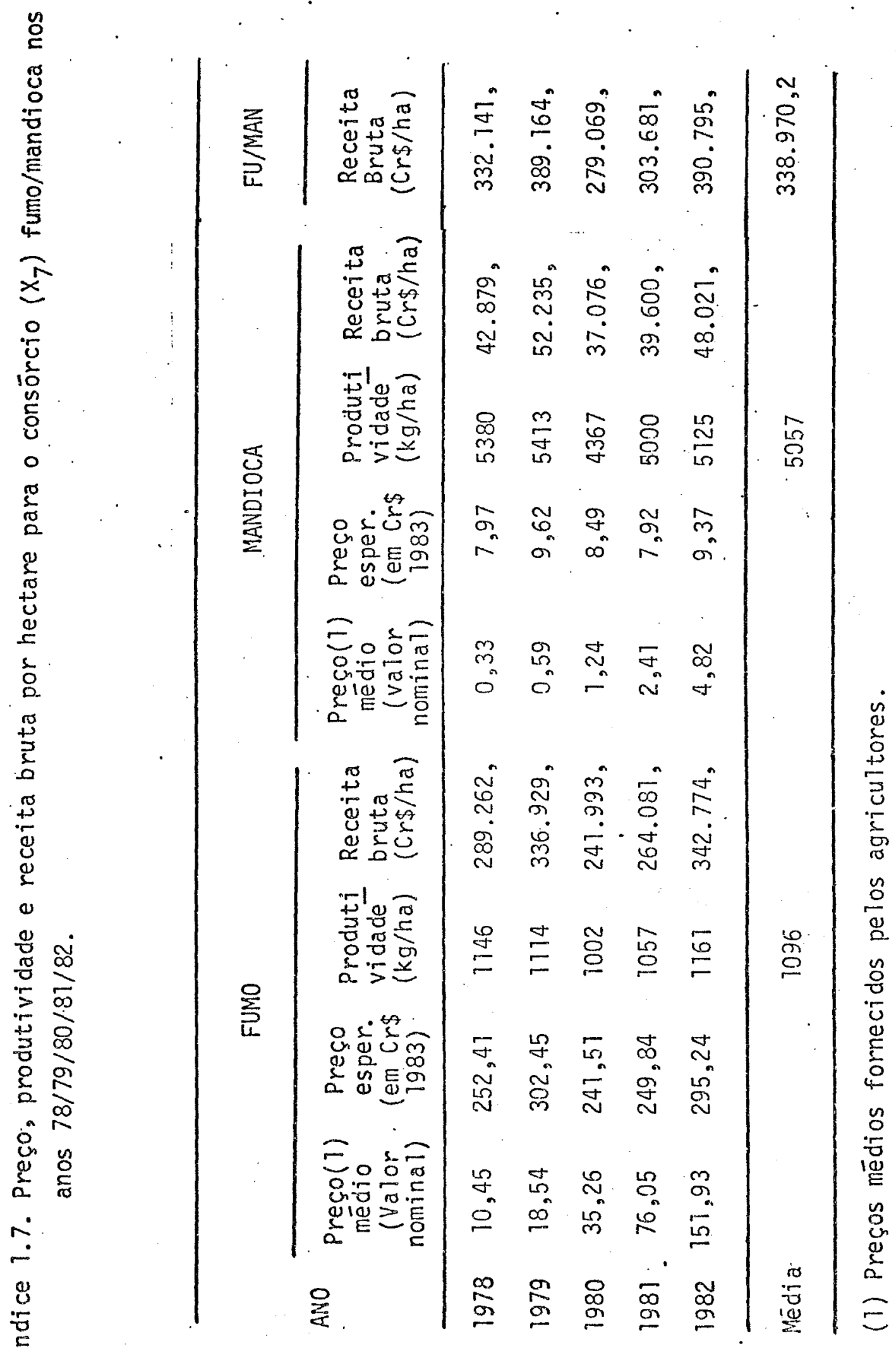


APẼNDICE II

- ExigénCia de fatoREs de PRODUgao dos CONSORCIOS DE CULTURAS SELECIONADOS NA AMOSTRA 
- Exigencia de fatores de produçäo para o consórcio $x_{1}$ (fumo / algodão/batata/feijão), por hectare. Arapiraca, Alágoas, 1983.

\begin{tabular}{lccc}
\hline & & & valor total \\
Item & Quantidade Unidade & $(6 r \$)$ \\
\hline
\end{tabular}

\section{Período I:}

- Adubo

Mão-de-obra

Periodo II:

Sement:e

Adubos

Mão-de-obra
321

25,28

19,70

1063,00

24,15 $\mathrm{kg}$

d/h al

$4.520,00$

-

4. 160,30

$74.360,00$

$\mathrm{d} / \mathrm{h}$ a $/$

$\mathrm{kg}$

- .

Periodo III:

- Defensivos

Antibrotante

Mão-de-obra

Período IV:

Pé de varal

Varas

Arame ou barbante

Mão-de-obra

$\begin{array}{cc}1,30 & 1 \\ 2,87 & 1 \\ 24,70 & \text { d/h a/ }\end{array}$

$5.880,00$

$5.970,00$

-

TOTAL

$\begin{array}{lcc}191 & \text { unid. } & 11.150,00 \\ 470 & \text { unid. } & 16.390,00 \\ 1,57 & \mathrm{~kg} & 1.200,00 \\ 36,43 & \mathrm{~d} / \mathrm{h} \text { al } & -\end{array}$

a/ $d / h=d i a s / h o m e m$

Fonte: Dados da amostra. 
71.

- Exigência de fatores de produção para o consōrcio $x_{2}$ (fumo/algodão/feijão) por hectare. Arapiraca, Alagoas, 1983.

\begin{tabular}{|c|c|c|c|}
\hline Item & Quantidade & Unidade & $\begin{array}{l}\text { Valor total } \\
\text { (Cr } \$ \text { ) }\end{array}$ \\
\hline
\end{tabular}

Período I:

Adubo

- Mão-de-obra
258

12,59 $\mathrm{kg}$

$\mathrm{d} / \mathrm{h} \underline{\mathrm{a}} \mathrm{l}$

$\because$

Periodo II:

Semente

Adubo

Mão-de-obrà

$\begin{array}{rl}17,70 & \mathrm{~kg} \\ 1.248,00 & \mathrm{~kg} \\ 24,32 & \mathrm{~d} / \mathrm{h} \text { al }\end{array}$

Periodo III:

Defensivos.

- Antibrotante

Mão-de-obra

Período IV:

Pé de varal

Varas

188

1,28

3,34

4,08

1

$4.220,00$

1

$6.160,00$

$d / h \underline{a} /$

Arame ou barbante

Mão-de-obra

533

2

40,86 unid.

unid.

$\mathrm{kg}$

$\mathrm{d} / \mathrm{h} \underline{\mathrm{a}} /$
$5.530,00$

$84.670,00$

$1.360,00$

$-$ 
- Exigēncia de fatores de produção para o consörcio $X_{3}$ (fumo/algodão/batata), por hectare. Arapiraca, Alagoas, 1983.

\begin{tabular}{|c|c|c|c|c|}
\hline I tem & Quantidade & Unidade & $\begin{array}{l}\text { Valor total } \\
\text { (Cr\$) }\end{array}$ & \\
\hline \multicolumn{5}{|l|}{ Perĩodo I: } \\
\hline Adubo & 328 & $\mathrm{~kg}$ & $2.830,00$ & \\
\hline Mão-de-obra & 19,58 & $\mathrm{~d} / \mathrm{h} \underline{\mathrm{a}} /$ & . & \\
\hline \multicolumn{5}{|l|}{ Perĩodo II: } \\
\hline Semente & 29,38 & $\mathrm{~kg}$ & $4.280,30^{\circ}$ & 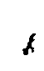 \\
\hline Adubo & 1888 & $\mathrm{~kg}$ & $80.410,00$ & \\
\hline Mão-de-obra & 28,31 & $\mathrm{~d} / \mathrm{h} \underline{a} /$ & - & \\
\hline \multicolumn{5}{|l|}{ Perīodo III: } \\
\hline Defensivos & 1,38 & 1 & $7.690,00$ & \\
\hline Antibrotante & 2,17 & 1 & $4.300,00$ & \\
\hline Mão-de-obra & 30,27 & $\mathrm{~d} / \mathrm{h} \underline{a} /$ & - & \\
\hline \multicolumn{5}{|l|}{ Perĩodo IV: } \\
\hline Pé de varal & 188 & unid. & $9.740,00$ & \\
\hline Varas & 888 & unid. & $20.410,00$ & \\
\hline Arame ou barbante & . 2,08 & $\mathrm{~kg}$ & $1.290,00$ & \\
\hline Mão-de-obra & 37,08 & $d / h \underline{a} /$ & - & \\
\hline TOTAL & & & $130.900,90$ & \\
\hline
\end{tabular}


- Exigência de fatores de produção para o consōrcio $x_{4}$ (fumo/feijão/mandio ca), por hectare. Arapiraca, Alagoas, 1983.

Quantidade Unidade $\quad$ Valor total
(Cr\$)

Período I:

$\begin{array}{lccc}\text {. Adubo } & 178 & \mathrm{~kg} & 1.970,00 \\ \text {. Mão-de-obra } & 25,47 & \mathrm{~d} / \mathrm{h} \text { a/ } & \ddots\end{array}$

Período II:

Semente

Adubo

Mão-de-obra

$\begin{array}{clr}0,28 & \mathrm{~kg} & 7.640,00 \\ 1358 & \mathrm{~kg} & 99.490,00 \\ 24,90 & \mathrm{~d} / \mathrm{h} \text { a } / & 24.675,90\end{array}$

Perīodo III :

Defensivos.

- Antibrotánte

Mão-de-obra

2,29

3,51

34,36

Perĩodo IV:

Pé de varal

Varas

Arame ou barbante

Mão-de-obra
282 854

2,75

32,82 unid.

- unid.

$\mathrm{kg}$

$\mathrm{d} / \mathrm{h} \underline{\mathrm{a}} /$

TOTAL

$164.600,00$

a/ $d / h=d i a s / h o m e m$

Fonte: Dados da amostra 
- Exigência de fatores de produção para o consōrcio $x_{5}$ (fumo/algodão), por hectare. Arapiraca, Alagoas, 1983.

Item Quantidade Unidade $\quad \begin{gathered}\text { Peso total } \\ \text { (Cr } \$)\end{gathered}$

\section{Período I:}

Adubo

Mão-de-obra

Período II:

Semente

Adubo

Mão-de-obra
355

12,83

18,35

$-$

24,62 $\mathrm{kg}$

$\mathrm{d} / \mathrm{h}$ a/
$3.150,00$

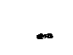

Perịodo III:

Defensivos.

Antibrotante

Mão-de-obra

$\begin{array}{cc}1,58 & 1 \\ 2,54 & 1 \\ 25,08 & \text { d/h al }\end{array}$

Período IV:

Pé de varal

128

unid.

$10.060,00$

Vara 1

524

- unid.

$16.830,00$

Arame ou barbante

2

Mão-de-obra

31,74

$\mathrm{kg}$

$1.410,00$

TOTAL

$127.840,00$

a/ $\mathrm{d} / \mathrm{h}=$ dias/homen

Fonte: Dados da amostra 
- Exigência de fatores de produção para o consörcio $x_{6}$ (fumo/feijão). por hectare. Arapiraca, Alagoas, 1983.

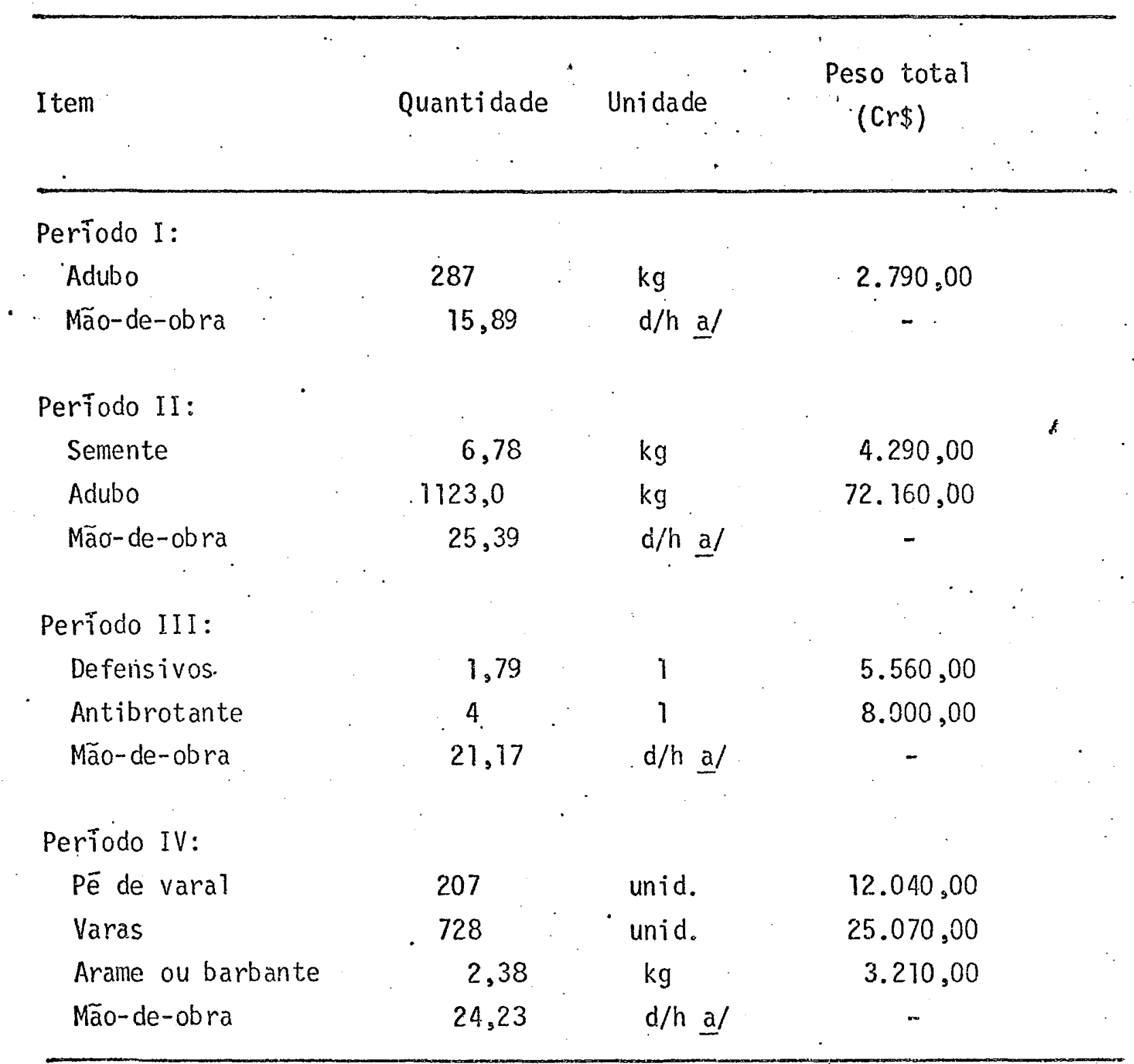

TOTAL

$133.120,00$

a/ $\mathrm{d} / \mathrm{h}=\mathrm{dias} / \mathrm{homem}$

Fonte: Dados da amostra 
- Exigencia de fatores de produção para o consörcio $x_{7}$ (fumo/mandioca), por hectare. Arapiraca, Alagoas, 1983.

$\begin{array}{lll} & \text { Quantidade Unidade } & \text { Vator total } \\ & (\operatorname{cr} \$)\end{array}$

Período I:

Adubo

Mão-de-obra

170

10,25

$\mathrm{kg}$

$1.090,00$

Máo-de-obra

Perĩodo II:

Semente

Adubo

Mão-de-obra

50

1365

25,12 $\mathrm{kg}$

$\mathrm{kg}$

$\mathrm{d} / \mathrm{h} \underline{\mathrm{a} /}$

$\mathrm{d} / \mathrm{h} \underline{\mathrm{a}} /$

-

Perĩodo III:

Defensivo

Antibrotante

Mão-de-obra.

$\begin{array}{rc}2,53 & 1 \\ 2,71 & 1 \\ 25,12 & \mathrm{~d} / \mathrm{h} \text { a } /\end{array}$

Periodo IV:

Pé de varal

81

309

Varas

Arame ou barbante

Mão-de-obra

1,58

22,98

\begin{tabular}{llr}
81 & unid. & $11.970,00$ \\
1,58 & unid. & $6.670,00$ \\
22,98 & $\mathrm{~kg}$ & $1.220,00$ \\
\hline & $\mathrm{d} / \mathrm{h}$ al & -
\end{tabular}

$130.810,00$

TOTAL

a/ $\mathrm{d} / \mathrm{h}=$ dias/homem

Fonte: Dados da amostra 
ApẼNDICE III

- Matriz utilizada na geracäo da fronteira EFICIENTE 
78.

- Matriz utilizada para geração da fronteira eficiente.

Linhas

G

OBJ

$L$

R1

L

L.

'R2

L

R3

L

L

L

$L$

L

L

L

L

L.

L

L

L.

L

L

L

L

L

L

L

G

G

G

$G$

$G$

. $G$

G

G

Lucro E 
- Matriz utilizada para geração da fronteira eficiente.

Colunas

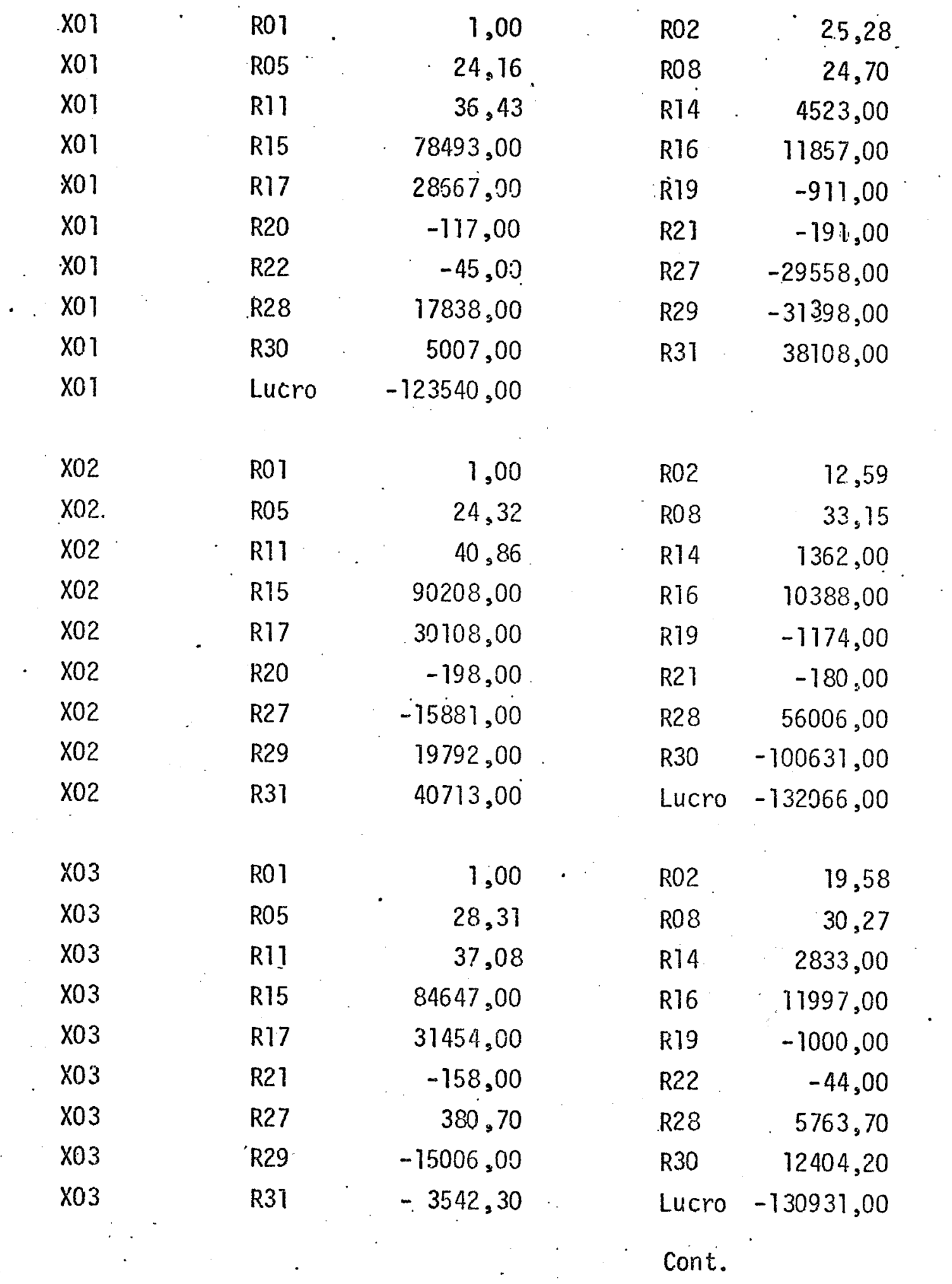


Colunas

X04

X04

$\times 04$

$\times 04$

$\times 04$

X0 4

$\times 04$

$\times 04$

$\times 04$

$\times 05$

$\times 05$

$\times 05$

X05

$\times 05$.

X05

$\times 05$

$\times 05$

X05

X06

$\times 06$

X06

X06

X06

X06

$\times 06$

X06

X06
ROI

R05

RII

R75

R17

R20

R27

R29

R31

R01

R05

R1 1

R15

R17

R21

R28

R30

Lucro

1,00

24,90

31,74

84558,00

28315,00

$-191,00$

32691,00

$-20388,00$

$-127948,00$

ROI

R05

R11

R15

R17

R20

R28

R30

Lucro
1,00

25,39

24,23

76460,00

40337,00

$-179,00$

46897,00

$-46899,00$

$-133147,00$
$\mathrm{RO2}$

R08

R14

R16

$\mathrm{R} 19$

R23

Rं28

R30

Lucro $-164638,00$

$\mathrm{RO} 2$

R08

R14

R16

R19

R27

R29

R31

$\mathrm{R} 02$

15,89

R08

21,17

R14

2729,00

R16 $\quad 13560,00$

R19 $-1049,00$

R27 $-10440,00$

$\mathrm{R} 29$

$-1157,00$

R31

11593,00

Cont. 
Colunas

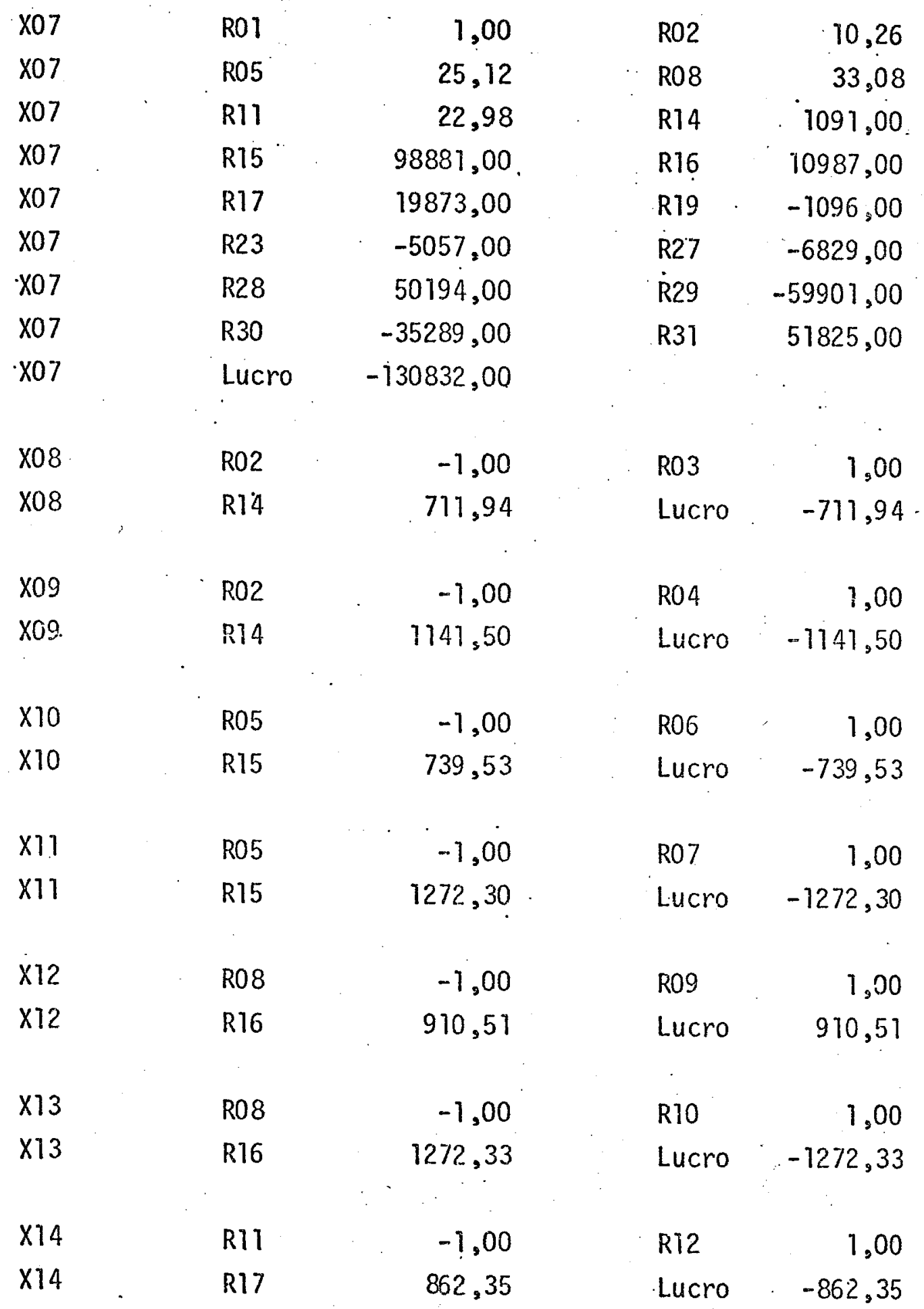

Cont. 
82.

Colunas

\begin{tabular}{|c|c|c|c|c|}
\hline$\times 15$ & $\mathrm{R} 11$ & $-1,00$ & R13 & 1,00 \\
\hline$\times 15$ & R17 & 1210,00 & Lucro & $-1210,00$ \\
\hline$\times 16$ & $\mathrm{R} 14$ & 1,00 & R15 & $-1,00$ \\
\hline$x 17$ & 15 & 1,00 & R 16 & $-1,00$ \\
\hline$\times 18$ & $\mathrm{R} 16$ & 1,00 & $\mathrm{R} 17$ & $-1,00$ \\
\hline$\times 19$ & R15 & $-0,50$ & R16 & $-0,25$ \\
\hline$\times 19$ & $\mathrm{R} 17$ & $-0,25$ & R18 & 1,00 \\
\hline$\times 19$ & Lucro & $-0,35$ & & \\
\hline$\times 20$ & R19 & 1,00 & Lucro & 253,00 \\
\hline$\times 21$ & $\mathrm{R} 20$ & 1,00 & $\mathrm{R} 24$ & 1,00 \\
\hline$x 22$ & $\mathrm{R} 20$ & 1,00 & Lucro & 86,00 \\
\hline$\times 23$ & $\mathrm{R} 21$ & 1,00 & Lucro & 80,00 \\
\hline$\times 24$ & $\mathrm{R} 22$ & 1,00 & R25 & 1,00 \\
\hline$\times 25$ & $\mathrm{R} 22$ & 1,00 & Lucro & 45,00 \\
\hline $\begin{array}{l}x 26 \\
x 26\end{array}$ & $\begin{array}{l}R 23 \\
R 23\end{array}$ & $\begin{array}{l}1,00 \\
1,00\end{array}$ & $\begin{array}{l}\text { R26 } \\
\text { R26 }\end{array}$ & $\begin{array}{l}1,00 \\
1,00\end{array}$ \\
\hline$x 27$ & $\mathrm{R} 23$ & 1,00 & Lucro & 11,00 \\
\hline$x 28$ & R24 & 1,00 & Lucro & $-86,00$ \\
\hline$\times 29$ & $\mathrm{R} 25$ & 1,00 & Lucro & $-45,00$ \\
\hline$\times 30$ & R26 & 1,00 & Lucro & $-17,00$ \\
\hline$x 31$ & $o b j$ & 1,00 & $\mathrm{R} 2 \mathrm{Z}$ & 1,00 \\
\hline$\times 32$ & $o b j$ & 1,00 & R28 & 1,00 \\
\hline$\times 33$ & $a b j$ & 1,00 & $\mathrm{R} 29$ & $1 ; 00$ \\
\hline$\times 3 \pi$ & obj & 1,00 & R30 & 1,00 . \\
\hline$\times 35$ & $o b j$ & 1,00 & R31 & 1,00 \\
\hline
\end{tabular}

